J. Phys. B: At. Mol. Opt. Phys., 27, (1994) p.429-446.

ISSN: 0953-4075/94/030429 + 18 ISSN (Online): 1361-6455

doi: $10.1008 / 0953-4075 / 27 / 3 / 010$

CIOP Publishing Ltd

This is an un-copyedited version of an article accepted for publication in J. Phys. B: At. Mol. Opt. Phys. IOP

Publishing Ltd is not responsible for any errors or omissions in this version of the manuscript or any version derived

from it. The definitive publisher authenticated version is available online at doi:10.1008/0953-4075/27/3/010.

http://journals.iop.org/

http://www.iop.org/EJ/journal/JPhysB

\title{
Atomic data for opacity calculations: XX. Photoionization cross sections and oscillator strengths for Fe II
}

\author{
Sultana N Nahar and Anil K Pradhan \\ Department of Astronomy, The Ohio State University, Columbus, OH 43210, USA
}

\begin{abstract}
Large scale ab initio calculations for the radiative data of Fe II have been carried out in the close coupling (cc) approbation employing the it-matrix method and a target state expansion consisting of $83 L S$ terms of Fe III. All bound states of Fe II with $n \leq 10$ and $l \leq 7$ are considered. The results include 1301 bound states in $L S$ coupling, oscillator strengths for 35941 transitions among the bound $L S$ states, and detailed photoionization cross sections for all bound states. Autoionizing resonances, as well as the coupling to excited core states, enhance the photoionization cross sections substantially. The calculations of oscillator strengths have been extended beyond the requirement of the Opacity Project to include a large number of fine structure transitions in Fe II, using an algebraic transformation of the $L S$ coupled line strength and the observed energies. The present $f$-values compare favourably with available experimental values and the calculations by Kurucz. However, the present results differ considerably from earlier 16 -state $R$-matrix calculations and the new radiative data yield Rosseland mean opacities that are 50\% higher. Some special features in the monochromatic opacity spectra of Fe II are also noted.
\end{abstract}

\section{Introduction}

Under the auspices of the Opacity Project (OP; Seaton 1987) ab initio calculations for accurate atomic radiative data for essentially all astrophysically abundant atoms and ions have been carried out by international collaborators, as reported in previous papers in this ADOC (Atomic Data for Opacity Calculations) series. The present work involves large scale computations for Fe II in the close coupling approximation, employing the $R$-matrix method as adapted for the OP. With many closely spaced energy levels, Fe II is a complex atomic system of 25 electrons where the electron correlation effects play a very important role. Recently Sawey and Berrington (1992) have reported $R$-matrix calculations for a few iron ions. Their Fe II calculations employed a close coupling (cc) expansion including only the states dominated by the $3 \mathrm{~d}^{6}$ ground configurations of the residual ion or the 'target' ion Fe III. As we show in the present, much more extended work, it is necessary to also include a large number of additional terms in the eigenfunction expansion, dominated especially by the excited $3 d^{5} 4 \mathrm{~s}$ and the $3 d^{5} 4 \mathrm{p}$ configurations, in order to obtain accurate radiative parameters. The aim of the present $R$-matrix close coupling calculations of Fe II is to take into account all the important states of Fe II in the wavefunction expansion and obtain more accurate radiative data for energy levels, oscillator strengths and photoionization cross sections. The importance of such calculations and a summary of theoretical details can be obtained in the first two papers of the ADOC series (Seaton 1987, Berrington et al 1987). In an earlier brief report 
(Le Dourneuf et al 1993), we reported the first detailed calculation, with autoionizing resonances and channel coupling effects, for the photoionization of the states with the ground state symmetry ${ }^{6} \mathrm{D}$. The present report is a complete account of the comprehensive calculations including 90 total Fe II symmetries, and photoionization of all bound states up to $n \leq 10$ and $l \leq 7$ and oscillator strengths of all possible bound-bound transitions among the 1301 computed states.

In addition to the extensive $L S$ coupling calculations for the OP calculations, we also obtain fine structure oscillator strengths for Fe II through an algebraic transformation of the $L S$ multiple line strengths and using observed spectroscopic energies. Most of the resulting fine structure $f$-values compare favourably with available experimental data, and rather better than those calculated by Kurucz (1981) using semi-empirical methods $\uparrow$. At present the data set by Kurucz is the only available source of Fe II $f$-values for most applications where a large number of transitions need to be considered. The present approach yields $f$-values for all transitions between the fine structure components of the dipole allowed $L S$ multiplets, given the observed energies of the individual components. Thus a reasonably complete data set for the large number of Fe II $f$-values is obtained.

\section{Target states}

Following the convention of collision theory, we refer to the ion in the e + ion system as the 'target' ion (also, as the 'core' or the 'residual' ion following photoionization). The importance of accurate target representation in cc calculations is to be emphasized as the necessary first step. For the cc calculations for Fe II we obtain the target eigenfunctions for Fe III using the SUPERSTRUCTURE program by Eissner et al (1974) based on a scaled Thomas-Fermi-Dirac potential and configuration interaction (CI) wave-functions. Given the number of states needed in the calculations, the atomic structure calculations are rather complicated since proper account needs to be taken of the CI effects, while the total number of configurations must be kept small to minimize, as much as possible, the memory of the CPU requirements. The task was found to be particularly difficult and time consuming for Fe III due to the large number of target states considered. The principal configurations (i.e. whose terms are explicitly included in the CC expansion) are: $3 d^{6}, 3 d^{5} 4 s$ and $3 d^{5} 4 p$. It might be noted here that it is the dipole core transitions between the even and the odd parity configurations that give rise to the well known photoexcitation-of-core (PEC) resonances in photoionization cross sections (Yu and Seaton 1987, Nahar and Pradhan 1991). The PEC resonances were not considered in the earlier work by Sawey and Berrington (1992) since the excited configurations were not included. As the $3 \mathrm{~d}$ shell plays the dominant role in electron correlation, the correlation configurations are constructed mainly with respect to variations in the $3 \mathrm{~d}$ orbital and excitations involving the $3 \mathrm{~d}$ electrons. In addition, important improvements in the accuracy of the Fe III energies and oscillator strengths were achieved by introducing a correlation configuration with the $4 \mathrm{~d}$ orbital (which increased the optimization time considerably). The final configuration list and the

$\dagger f$-values given in this paper correspond to the most recent gf values calculated by him which were obtained from him by private communication. 
Thomas-Fermi scaling parameters $\lambda_{n l}$ are given in table 1 . The choice of the target states actually included in the cc calculations was somewhat independent of the target optimization since all 136 $L S$ terms dominated by the three principal configurations, $3 \mathrm{~d}^{6}, 3 \mathrm{~d}^{5} 4 \mathrm{~s}$ and $3 \mathrm{~d}^{5} 4 \mathrm{p}$, are well represented with the choice of the target in table 1. We include up to 83 terms in the present Fe II calculations. In particular we include all odd parity terms dominated by $3 d^{5} 4 p$ that are linked via dipole transitions to the ground state ${ }^{5} \mathrm{D}$ to take account of strong PEC resonances in the photoionization cross sections.

Table 1 compares the energies of the 83 terms of Fe III with the observed values (Sugar and Corliss 1985, Moore 1952). It may be noted that three calculated singlet terms: $3 d^{6}\left({ }^{1} \mathrm{D},{ }^{1} \mathrm{~S}\right), 3 \mathrm{~d}^{5}$ ${ }^{2} \mathrm{~S} 4 \mathrm{~s}{ }^{1} \mathrm{~S}$, have not been observed. Comparison of the calculated target energies with the observed energies shows agreement within $10 \%$ for most of the states, the largest discrepancy being about $18 \%$ for the $3 \mathrm{~d}^{6}{ }^{1}$ I state.

Over 300 dipole oscillator strengths were obtained from SUPERSTRUCTURE for the $L S$ target states dominated by the $3 d^{6,} 3 d^{5} 4 s$ and $3 d^{5} 4 p$ configurations. These oscillator strengths show agreement between the length and the velocity forms within $15 \%$ for most of the transitions in $\mathrm{Fe}$ III, further confirming the overall accuracy of the large set of the target eigenfunctions.

In table 1 , the notations $\mathrm{O}, \mathrm{S}, \mathrm{Q}$ and $\mathrm{D}$ in the target state column specify that the corresponding Fe III state couples to octet, sextet, quartet or doublet symmetry of the e + ion system, $S L \pi$, of Fe II respectively. Thus there are $2 \mathrm{O}, 21 \mathrm{~S}, 58 \mathrm{Q}$ and $62 \mathrm{D}$ such terms of Fe III that are in the target expansion for radiative calculations of octet, sextet, quartet and doublet states of Fe II. In table 1 , the number next to each notation of $\mathrm{O}, \mathrm{S}, \mathrm{Q}$ and $\mathrm{D}$ is the energy degeneracy number for that state. This will be explained in the following section.

\section{Computations and calculations for the radiative data}

As in the case of all OP work, the present computations have been carried out in $L S$ coupling, that is, relativistic effects are not taken into account. Since Fe II is a singly charged ion, it has been assumed that $L S$ coupling would provide a good approximation for the radiative data. All bound states, denoted as $S_{t} L_{t} n l$, where $S_{\mathrm{t}} L_{\mathrm{t}}$ is a target state, and $n \leq 10$ and $l \leq 7$ are considered for the radiative data.

Each excited target state $S_{\mathrm{t}} L_{\mathrm{t}}$ of the ion is the series limit for the Rydberg series $S_{t} L_{t} v l$ of the $(N+1)$ electron system, where $v$ is the effective quantum number of the $(N+1)$ th electron. These are pure bound states if they lie below the first ionization threshold, but those that lie above the first ionization threshold are usually quasibound states and manifest themselves through autoionizing resonances in the photoionization cross sections (some states above the first ionization threshold may be pure bound states in $L S$ coupling if they are forbidden to autoionize into the corresponding continua). These Rydberg resonances repeat the pattern for each increment of $v$. As $v$ increases, the resonances get narrower and numerical resolution becomes difficult. To obviate the problem, we employ a constant mesh in $v$, for each interval $v$ and $v+1$, to fully delineate the Rydberg resonances up to $v=10$ with a mesh interval of $\Delta v=0.01$. The region $10<v$

$\leq \infty$ that we term as the QDT region, corresponds to a small energy region which is treated through quantum defect theory (QDT) using the Gailitis averaging method (e.g. Nahar and Pradhan 1991).

For closely spaced target states, as in the case of Fe III, the QDT region of different target 
states may overlap. Such target states with overlapping QDT regions are treated

Table 1. Calculated (cal) term energies of Fe III (configurations $3 d^{4}, 3 d^{5} 4 s$ and $3 d^{5} 4 p$ ) and comparison with the observed (obs) energies. The energies, in Ry, are relative to the $3 \mathrm{~d}^{65} \mathrm{D}$ ground state. The three states, $3 \mathrm{~d}^{5} 4 \mathrm{~s}$ ' $\mathrm{S}, 3 \mathrm{~d}^{6}$ ' $\mathrm{D}$ and $3 \mathrm{~d}^{6}$ ' $\mathrm{S}$, are unobserved. The notation $\mathrm{O}, \mathrm{S}, \mathrm{Q}$ and $\mathrm{D}$ in the target state column specifies the coupling to the octet, sextet, quartet and doublet symmetries of Fe II respectively, The number next to them represents the degeneracy index (see text). The spectroscopic and correlation configurations for Fe III and the values of scaling parameter $\lambda_{n l}$ for each orbital in the Thomas-Fermi potential are also given.

\begin{tabular}{|c|c|c|c|c|c|c|}
\hline \multirow[b]{3}{*}{1} & \multirow[b]{2}{*}{ State } & & \multicolumn{2}{|c|}{ Energy } & \multirow{2}{*}{\multicolumn{2}{|c|}{ Target states }} \\
\hline & & & Obs. & Calc. & & \\
\hline & $3 d^{6}$ & ${ }^{5} \mathrm{D}$ & 0.0 & 0.0 & [S1 & $\overrightarrow{\mathrm{Q1}]}$ \\
\hline 2 & $3 d^{6}$ & ${ }^{3} \mathrm{P} 2$ & 0.1826 & 0.1810 & [Q2 & Di] \\
\hline 3 & $3 d^{6}$ & ${ }^{3} \mathrm{H}$ & 0.1845 & 0.2163 & [Q3 & D2] \\
\hline 4 & $3 d^{6}$ & ${ }^{3} \mathrm{~F} 2$ & 0.1972 & 0.2105 & QQ3 & D2] \\
\hline 5 & $3 d^{6}$ & ${ }^{3} \mathrm{G}$ & 0.2263 & 0.2537 & QQ3 & D2] \\
\hline 6 & $3 d^{5}\left({ }^{6} s\right) 4 s$ & ${ }^{7} S$ & 0.2742 & 0.2728 & [01 & S2] \\
\hline 7 & $3 \mathrm{~d}^{6}$ & ${ }^{1}$ & 0.2766 & 0.3246 & [D3 & \\
\hline 8 & $3 d^{6}$ & ${ }^{3} \mathrm{D}$ & 0.2805 & 0.3037 & IQ4 & D3] \\
\hline 9 & $3 d^{6}$ & 'G2 & 0.2815 & 0.3021 & [ & D3] \\
\hline 10 & $3 d^{6}$ & 's2 & 0.3172 & 0.3190 & [ & D3] \\
\hline 11 & $3 d^{6}$ & ${ }^{1} \mathrm{D} 2$ & 0.3263 & 0.3460 & [ & D3j \\
\hline 12 & $3 d^{5}\left({ }^{6} s\right) 4 s$ & ${ }^{s} \mathrm{~S}$ & 0.3736 & 0.4167 & [S3 & Q5] \\
\hline 13 & $3 d^{6}$ & ${ }^{1} \mathrm{~F}$ & 0.3909 & 0.4295 & [ & D4] \\
\hline 14 & $3 d^{6}$ & ${ }^{3} \mathrm{Pl}$ & 0.4556 & 0.4900 & [Q6 & DS] \\
\hline 15 & $3 d^{6}$ & ${ }^{3} \mathrm{~F} 1$ & 0.4580 & 0.4985 & [Q6 & D5] \\
\hline 16 & $3 d^{6}$ & ${ }^{1} \mathrm{G} 1$ & 0.5214 & 0.5738 & [ & D6] \\
\hline 17 & $3 d^{5}\left({ }^{4} G\right) 4 s$ & ${ }^{5} \mathrm{G}$ & 0.5783 & 0.5995 & [S4 & Q7] \\
\hline 18 & $3 d^{5}\left({ }^{4} P\right) 4 s$ & ${ }^{5} \mathrm{P}$ & 0.6061 & 0.6466 & [S\$ & Q8] \\
\hline 19 & $3 d^{5}\left({ }^{4} D\right) 4 s$ & ${ }^{5} \mathrm{D}$ & 0,6358 & 0.6730 & [S5 & Q8] \\
\hline 20 & $3 d^{5}\left({ }^{4} G\right) 4 s$ & ${ }^{3} G$ & 0.6444 & 0.6957 & [Q9 & D7] \\
\hline 21 & $3 d^{5}\left({ }^{4} P\right) 4 s$ & ${ }^{3} \mathrm{P}$ & 0.6724 & 0.7438 & [Q9 & D7] \\
\hline 22 & $3 d^{5}\left({ }^{4} D\right) 4 s$ & ${ }^{3} \mathrm{D}$ & 0.7019 & 0.7691 & [Q10 & D8] \\
\hline 23 & $3 d^{5}\left({ }^{2} I\right) 4 s$ & ${ }^{3} \mathrm{I}$ & 0.7276 & 0.7526 & [Q10 & D8] \\
\hline 24 & $3 d^{5}\left({ }^{6} S\right) 4 p$ & ${ }^{7} \mathrm{P}^{0}$ & 0.7516 & 0.7338 & $\mathrm{OO}_{2}$ & S6] \\
\hline 25 & $3 d^{6}$ & ${ }^{1} \mathrm{D}$ & & 0.7650 & i & D81 \\
\hline 26 & $3 \mathrm{~d}^{5}\left({ }^{2} \mathrm{D} 3\right) 4 \mathrm{~s}$ & ${ }^{3} \mathrm{D}$ & 0.7510 & 0.8126 & [Q1! & D9] \\
\hline 27 & $3 d^{5}\left({ }^{4} F 3\right) 4 s$ & ${ }^{5} \mathrm{~F}$ & 0.7585 & 0.8038 & [S6 & Q11] \\
\hline 28 & $3 d^{5}\left({ }^{2} I\right) 4 s$ & $i_{1}^{*}$ & 0.7603 & 0.8005 & [ & D9] \\
\hline 29 & $3 d^{5}\left({ }^{2} F 2\right) 4 s$ & ${ }^{3} \mathrm{~F}$ & 0.7689 & 0.8211 & [Q11 & D9] \\
\hline 30 & $3 d^{5}\left({ }^{2} D 3\right) 4 s$ & 'D & 0.7914 & 0.8601 & [ & Dio] \\
\hline 31 & $3 d^{5}\left({ }^{2} F 2\right) 4 s$ & 'F & 0.8010 & 0.8693 & I & DIO] \\
\hline 32 & $3 d^{5}\left({ }^{2} \mathrm{H}\right) 4 \mathrm{~s}$ & ${ }^{3} \mathrm{HI}$ & 0.8090 & 0.8524 & ¿Q12 & D10\} \\
\hline 33 & $3 d^{5}\left({ }^{6} S\right) 4 p$ & ${ }^{s} \mathrm{P}^{0}$ & 0.8133 & 0.8295 & [S7 & Q [2] \\
\hline 34 & $3 d^{5}\left({ }^{2} G 2\right) 4 s$ & ${ }^{3} \mathrm{G}$ & 0.8184 & 0.8679 & [Q13 & D10] \\
\hline 35 & $3 d^{5}\left({ }^{4} F\right) 4 s$ & ${ }^{3} \mathrm{~F}$ & 0.8244 & 0.8991 & [Q13 & D11] \\
\hline 36 & $3 d^{5}\left({ }^{2} \mathrm{H}\right) 4 \mathrm{~s}$ & ${ }^{1} \mathrm{H}$ & 0.8431 & 0,9000 & [ & D1II \\
\hline 37 & $3 \mathrm{~d}^{5}\left({ }^{2} \mathrm{FI}\right) 4 \mathrm{~s}$ & ${ }^{3} \mathrm{~F}$ & 0.8511 & 0.9106 & [Q13 & DII] \\
\hline 38 & $3 d^{5}\left({ }^{2} G 2\right) 4 s$ & ${ }^{t} G$ & 0.8521 & 0.9168 & 1 & DI1] \\
\hline 39 & $3 d^{5}\left({ }^{2} F 1\right) 4 s$ & ${ }^{t} \mathrm{~F}$ & 0.8843 & 0.9582 & [ & D12] \\
\hline 40 & $3 d^{6}$ & 's & & 0.9596 & [ & D12] \\
\hline 41 & $3 d^{5}\left({ }^{2} s\right) 4 s$ & ${ }^{3} \mathrm{~s}$ & 0.8991 & 0.9721 & [Q14 & D12] \\
\hline 42 & $3 d^{5}\left({ }^{2} D 2\right) 4 s$ & ${ }^{3} \mathrm{D}$ & 0.9652 & 1.0406 & [Q15 & D13] \\
\hline 43 & $3 d^{5}\left({ }^{2} D 2\right) 4 s$ & ${ }^{1} \mathrm{D}$ & 0.9985 & 1.0908 & [ & DI3] \\
\hline 44 & $3 d^{5}\left({ }^{4} G\right) 4 p$ & ${ }^{5} G^{n}$ & 1.0358 & 1.0353 & [S8 & Q15] \\
\hline 45 & $3 d^{5}\left(^{2} S\right) 4 s$ & 'S & & 1.0310 & [ & D13j \\
\hline 46 & $3 d^{5}\left({ }^{2} G I\right) 4 s$ & ${ }^{3} \mathrm{G}$ & 1.0419 & 1.1137 & [Q16 & D14] \\
\hline 47 & $3 d^{5}\left({ }^{4} G\right) 4 p$ & ${ }^{s} \mathrm{H}^{0}$ & 1.0512 & 1.0507 & {$[S 9$} & Q16] \\
\hline
\end{tabular}


Table 1. (continued)

\begin{tabular}{|c|c|c|c|c|c|c|}
\hline \multirow[b]{3}{*}{48} & \multirow[b]{2}{*}{ State } & & \multicolumn{2}{|c|}{ Energy } & \multirow{2}{*}{\multicolumn{2}{|c|}{ Target states }} \\
\hline & & & Obs. & Calc. & & \\
\hline & $3 d^{5}\left({ }^{4} G\right) 4 p$ & ${ }^{5} F^{0}$ & 1.0619 & 1.0717 & [S9 & Q16 \\
\hline 49 & $3 d^{5}\left({ }^{4} P\right) 4 p$ & ${ }^{s} S^{\ominus}$ & 1.0653 & 1.0846 & [s9 & Q16 \\
\hline 50 & $3 d^{5}\left({ }^{4} P\right) 4 p$ & ${ }^{5} D^{\circ}$ & 1.0661 & 1.0825 & {$[s 9$} & Q16 \\
\hline 51 & $3 d^{5}\left({ }^{2} G 1\right) 4 s$ & 'G & 1.0748 & 1.1619 & i & Di4 \\
\hline 52 & $3 d^{5}\left({ }^{4} G\right) 4 p$ & ${ }^{3} \mathrm{~F}^{\circ}$ & 1.0778 & 1.0965 & Q16 & D14 \\
\hline 53 & $3 d^{5}\left({ }^{4} G\right) 4 p$ & ${ }^{3} \mathrm{H}^{\mathrm{o}}$ & 1.0800 & 1.0963 & [Q16 & D14 \\
\hline 54 & $3 d^{5}\left({ }^{4} P\right) 4 p$ & ${ }^{s} \mathrm{p}^{o}$ & 1.0810 & 1.1083 & [S9 & Q16 \\
\hline 55 & $3 d^{5}\left({ }^{4} P\right) 4 p$ & ${ }^{3} \mathrm{P}^{\circ}$ & 1.0921 & 1.1257 & {$[\mathrm{Q} 17$} & D14 \\
\hline 56 & $3 d^{5}\left(^{4} D\right) 4 p$ & ${ }^{s} F^{o}$ & 1.1041 & 1.1220 & {$[\$ 10$} & Q17] \\
\hline 57 & $3 d^{5}\left({ }^{4} G\right) 4 p$ & ${ }^{3} \mathrm{G}^{\circ}$ & 0.1112 & 1.1475 & [Q17 & D14 \\
\hline 58 & $3 d^{5}\left({ }^{4} P\right) 4 p$ & ${ }^{3} \mathrm{D}^{\circ}$ & 1.1167 & 1.1567 & [Q17 & D14 \\
\hline 59 & $3 d^{5}\left({ }^{4} D\right) 4 p$ & ${ }^{5} D^{\circ}$ & 1.1208 & 1.1449 & [\$10 & Q17] \\
\hline 60 & $3 d^{5}\left({ }^{4} D\right) 4 p$ & ${ }^{5} \mathrm{p}^{0}$ & 1.1272 & 1.1509 & i\$10 & Q17] \\
\hline 61 & $3 d^{5}\left({ }^{4} D\right) 4 p$ & ${ }^{3} D^{\circ}$ & 1.1381 & 1.1721 & [Q18 & Dis \\
\hline 62 & $3 d^{5}\left({ }^{4} D\right) 4 p$ & ${ }^{3} \mathbf{F}^{\circ}$ & 1.1442 & 1.1784 & [Q18 & D15 \\
\hline 63 & $3 d^{5}\left({ }^{4} P\right) 4 p$ & ${ }^{3} \mathrm{~S}^{\circ}$ & 1.1518 & 1.2158 & [Q18 & D15 \\
\hline 64 & $3 d^{5}\left({ }^{4} D\right) 4 p$ & ${ }^{3} \mathrm{P}^{0}$ & 1.1733 & 1.2231 & [Q18 & D15 \\
\hline 65 & $3 d^{5}\left({ }^{2} \mathrm{I}\right) 4 \mathrm{p}$ & ${ }^{3} \mathrm{~K}^{\circ}$ & 1.1873 & 1.1884 & [Q18 & D15 \\
\hline 66 & $3 d^{5}\left({ }^{2} x\right) 4 p$ & ${ }^{3} \mathrm{I}^{\circ}$ & 1.1912 & 1.1932 & [Q18 & D15] \\
\hline 67 & $3 d^{5}\left({ }^{2} I\right) 4 p$ & ' $\mathrm{H}^{\circ}$ & 1.2002 & 1.2104 & i & D15] \\
\hline 68 & $3 d^{5}\left({ }^{2} I\right) 4 p$ & ' $\mathrm{K}^{\circ}$ & 1.2028 & 1.2102 & {[} & D15] \\
\hline 69 & $3 d^{5}\left({ }^{2} D\right) 4 p$ & ${ }^{3} \mathrm{~F}^{0}$ & 1.2064 & 1.2815 & [Q18 & D15] \\
\hline 70 & $3 d^{5}\left({ }^{2} I\right) 4 p$ & ${ }^{3} \mathrm{H}^{\circ}$ & 1.2072 & 1.2223 & [Q18 & D15] \\
\hline 71 & $3 d^{5}\left(^{2} D\right) 4 p$ & $\mathrm{D}^{\circ}$ & I.1978 & 1.2375 & i & D 15 \\
\hline 72 & $3 d^{5}\left({ }^{2} D\right) 4 p$ & ${ }^{3} \mathrm{P}^{\circ}$ & 1.2252 & 1.2698 & [Q18 & D15] \\
\hline 73 & $3 d^{5}\left({ }^{2} F\right) 4 p$ & ${ }^{\prime} G^{\circ}$ & 1.2244 & 1.2554 & 8 & D15] \\
\hline 74 & $3 d^{5}\left({ }^{2} F\right) 4 p$ & ${ }^{3} \mathrm{G}^{\circ}$ & 1.2320 & 1.2635 & [Q18 & D15] \\
\hline 75 & $3 d^{5}\left({ }^{4} F\right) 4 p$ & ${ }^{5} G^{\circ}$ & 1.2339 & 1.2602 & {$[\mathrm{~S} 11$} & Q18] \\
\hline 76 & $3 d^{5}\left({ }^{2} D\right) 4 p$ & ${ }^{3} \mathrm{D}^{\circ}$ & 1.2313 & 1.2790 & [Q18 & DIS \\
\hline 77 & $3 d^{5}\left(a^{2} F\right) 4 p$ & ${ }^{3} \mathrm{D}^{\circ}$ & 1.2413 & 1.2859 & [Q18 & DIS] \\
\hline 78 & $3 d^{5}\left({ }^{2} I\right) 4 p$ & ${ }^{1} \mathbf{I}^{\circ}$ & 1.2369 & 1.2618 & I & $D(5]$ \\
\hline 79 & $3 d^{5}\left({ }^{2} D\right) 4 p$ & ${ }^{1} \mathrm{~F}^{\circ}$ & 1.2411 & $1.274 !$ & i & DIS] \\
\hline 80 & $3 d^{3}\left({ }^{4} F\right) 4 p$ & ${ }^{5} \mathrm{~F}^{\circ}$ & 1.2402 & 1.2716 & {$[\mathrm{~S} 11$} & Q18] \\
\hline 81 & $3 d^{5}\left(a^{2} F\right) 4 p$ & ${ }^{3} F^{0}$ & 1.2453 & 1.2347 & [Q18 & Di5] \\
\hline 82 & $3 d^{5}\left({ }^{4} F\right) 4 p$ & ${ }^{5} D_{0}$ & 1.2520 & 1.2847 & [S11] & Q18] \\
\hline 83 & $3 \mathrm{~d}^{5}\left({ }^{2} \mathrm{H}\right) 4 \mathrm{p}$ & ${ }^{3} \mathrm{H}^{0}$ & 1.2566 & 1.2781 & [Q18 & D15] \\
\hline
\end{tabular}

Fe III configurations:

Spectroscopic: $1 s^{2} 2 s^{2} 2 p^{6} 3 s^{2} 3 p^{6} 3 d^{6}, 1 s^{2} 2 s^{2} 2 p^{6} 3 s^{2} 3 p^{6} 3 d^{5} 4 s, 1 s^{2} 2 s^{2} 2 p^{6} 3 s^{2} 3 p^{6} 3 d^{5} 4 p$ Correlation: $1 s^{2} 2 s^{2} 2 p^{6} 3 s^{2} 3 p^{4} 3 d^{8}, 1 s^{2} 2 s^{2} 2 p^{6} 3 p^{6} 3 d^{8}, 1 s^{2} 2 s^{2} 2 p^{6} 3 s^{2} 3 p^{6} 3 d^{7}$, $1 \mathrm{~s}^{2} 2 \mathrm{~s}^{2} 2 \mathrm{p}^{6} 3 \mathrm{~s}^{3} \mathrm{p}^{5} 3 \mathrm{~d}^{8}, 1 \mathrm{~s}^{2} 2 \mathrm{~s}^{2} 2 \mathrm{p}^{6} 3 \mathrm{~s}^{2} 3 \mathrm{p}^{6} 3 \mathrm{~d}^{5} 4 \mathrm{~d}$ $\lambda_{n l}: 1.1(1 \mathrm{~s}) 1.1(2 \mathrm{~s}), 1.1(2 \mathrm{p}), 1.095(3 \mathrm{~s}), 1.091(3 \mathrm{p}), 1.0341(3 \mathrm{~d}) 1.04351(4 \mathrm{~s})$ $1.04466(4 \mathrm{p}), 1.27865(4 \mathrm{~d})$

as degenerate in the present radiative calculations. We expect little consequent loss of accuracy since most of these states lie fairly high in energy. In table 1, the number of such terms that are treated degenerate is given next to the notation $\mathrm{O}, \mathrm{S}, \mathrm{Q}$ and $\mathrm{D}$, mentioned earlier.

Following the $R$-matrix calculations for the e + Fe III system, we first obtain the energy levels of Fe II for all $S L \pi$ symmetries considered. For complex atoms and ions isoelectronic with the third and the fourth row elements, it is a non-trivial task to identify all the computed levels and a careful analysis is required based partly on a study of quantum defects along overlapping 
Rydberg series, and partly on the contributions of the closed channel wavefunctions, in the region outside the $R$-matrix boundary, to the total bound state. Nearly all Fe II states have been unambiguously identified. It might be noted that for the calculation of opacities the level identification problem is not consequential. However, we strive to attain precise $L S$ term designations in order to facilitate other applications of the present data, particularly in the important extension of the OP work to obtain $f$-values for fine structure components within $L S$ mutiplets.

The work on Fe II was carried out on the 8 processor 64 MW Cray Y-MP at the Ohio Supercomputer Center, Columbus, Ohio. Table 2 shows the total CPU time required for the radiative calculations for octet, sextet, quartet and doublet symmetries, and the maximum memory needed for the $R$-matrix close coupling calculations with 83 state expansion for Fe II. It required up to $20 \mathrm{MW}$ of memory for the largest $S L \pi s$ and a total of about $450 \mathrm{CPU}$ hours. Work was divided according to different symmetries, and the table shows the number of target states coupled to each $S L \pi$ and used as the target set of eigenfunctions for radiative calculations for that particular symmetry. For the largest of the quartet and doublet symmetries, the $R$-matrix calculations could be carried out for onlv one $S L \pi$ at a time.

Table 2. Summary of the radiative calculations for Fe II : $N_{\mathrm{CC}}$ is the number of target states coupled to a particular spin symmetry of Fe II, CPU is the amount of time required for that symmetry. Maximum memory requirement and disk space for a typical quartet or doublet symmetry run are given below. $N_{S L \pi}$ the total number of bound symmetries, $S L \pi$ shows the range of these symmetries and $N_{E_{T}}$ is the corresponding number of bonnd states up to $n \leq 10, l \leq 7 . N_{b n d}$ is the number of bound states below the first ionization threshold, $N_{f}$ is the number of oscillator strengths. The largest case is $S L \pi=2 G$ with 181 continuum channels and the hamiltonian matrix size of 2228. Memory and disk space range requirements: RAM: $20 \mathrm{MW}$, disk: 3.5-4 GB.

\begin{tabular}{|c|c|c|c|c|c|c|c|}
\hline Symmetry & $N_{C C}$ & CPU & $N_{S L \pi}$ & $S L \pi$ (range) & $N_{E \mathrm{~S}}$ & $N_{\text {bnd }}$ & $N_{f}$ \\
\hline Octets & 2 & $1.2 \mathrm{~min}$ & 16 & ${ }^{8} \mathrm{~S}-{ }^{8} \mathrm{~L},{ }^{\mathrm{R}} \mathrm{S}^{n}-{ }^{8} \mathrm{~K}^{0}$ & 92 & 6 & 95 \\
\hline Sextets & 21 & $4.2 \mathrm{~h}$ & 25 & ${ }^{6} \mathrm{~S}-{ }^{6} \mathrm{~N},{ }^{6} \mathrm{~S}^{0}{ }^{6} \mathrm{O}^{\circ}$ & 234 & 205 & 4267 \\
\hline Quartets & 58 & $166.5 \mathrm{~h}$ & 29 & ${ }^{4} \mathrm{~S}-{ }^{4} \mathrm{~T},{ }^{4} \mathrm{~S}^{0}-{ }^{4} \mathrm{R}^{0}$ & 357 & 308 & 9965 \\
\hline Doublets & 62 & $174.6 \mathrm{~h}$ & 20 & ${ }^{2} \mathrm{~S}-{ }^{2} \mathrm{M},{ }^{2} \mathrm{~S}^{\circ}-{ }^{2} \mathrm{M}^{\circ}$ & 618 & 224 & 21614 \\
\hline Total & 83 & $446 \mathrm{~h} \dagger$ & 90 & & 1301 & 743 & 35941 \\
\hline
\end{tabular}

$\uparrow$ Including about $100 \mathrm{CPU}$ h spent on trials and problems

\section{Results and discussions}

Three sets of data are calculated: (a) energy levels, (b) oscillator strengths and (c) photoionization cross sections; these are discussed below with selected examples.

\subsection{Energy levels}

We obtain $1301 L S$ bound state and identify 743 states that lie below the first ionization threshold of Fe II, i.e. below the $3 d^{6}\left({ }^{5} \mathrm{D}\right)$ ground state of Fe III. In addition, a few bound states are obtained that lie above the ionization threshold but are forbidden to autoionize in $L S$ coupling. The number of bound states that have been identified are more than twice the number that have been reportedly observed. Table 2 gives a summary of the number of bound state symmetries $S L \pi$, their total $L$ and $S$ value ranges, and the corresponding number of bound states computed for each $S L \pi$. All of the observed $L S$ terms, 266 in total, have been calculated and identified. This could not have been 
possible with the earlier 16-cc $R$-matrix calculations (Savvey and Berrington 1992) because several of the observed states couple to terms dominated by excited configurations $3 d^{5} 4 \mathrm{~s}$ and $3 d^{5} 4 p$ of Fe III which are not included in the earlier work. The present calculated energy for the $3 d^{6} 4 s\left({ }^{6} \mathrm{D}\right)$ ground state of Fe II differs by $0.6 \%$ from the observed value, compared to a $7 \%$ discrepancy in the previous calculation.

In table 3 we compare the calculated and observed energies. The latter set includes recent measurements from the Lund group (Johansson 1992); the $L S$ energies have been computed as the statistically weighted average over the fine structure components. In a small number of cases the set of observed fine structure levels is incomplete; such states are marked with asterisks. Comparison shows that most of the calculated $L S$ term energies are within $10 \%$ of the observed ones, yet many do show larger differences of up to 10-30\%. Exclusion of relativistic effects is probably the prime contributor to the discrepancies. While the relativistic calculations are planned, as part of a new project on the iron-peak elements (the Iron Project), using Breit-Pauli $R$-matrix method, it is estimated that the $a b$ initio fine structure calculations may require an order of magnitude more resources and effort even over the present one.

\subsection{Oscillator strengths}

Dipole oscillator strengths ( $f$-values) for approximately 36000 transitions among the 1301 calculated bound states of Fe II are obtained in $L S$ coupling. Over 19000 of these transitions are between bound states which lie below the first ionization threshold. For opacity calculations we also include transitions of bound states when the lower state lies below the first ionization threshold and the upper state lies above; since the latter do not appear as resonances in the photoionization cross sections in $L S$ coupling but the corresponding oscillator strength does contribute to total photoabsorption. Table 2 lists the number of oscillator strengths obtained for each spin symmetry and all corresponding total angular momenta $L$. Each oscillator strength in $L S$ coupling corresponds to a number of transitions, when we consider the fine structure, resulting in over 100000 individual $f$-values. These calculations are discussed below.

As an enormous amount of data have been computed, one of the primary aims of this report is to attempt to establish the uncertainties involved relative to available experimental data and previous theoretical calculations. Table 4(a) presents selected comparisons with other results found in literature. The present oscillator strengths are obtained from the calculated line strength $(s)$, and the observed energies, according to the relation, $S=\left(3 \mathrm{~g}_{\mathrm{r}} / \mathrm{E}_{\mathrm{fi}}\right) f_{i f}$. Of the two sets of columns for transition of states in the table, the first set of columns compares the present results with both the measured values compiled by NIST (Fuhr et al 1988) and the calculated ones by Kurucz (1981), and the second set of columns with those of Kurucz. NIST has compiled and evaluated all the available measured and some theoretical values for the oscillator strengths. The column listing the NIST $f$-values for dipole allowed transitions in $L S$ coupling are averaged over the fine structure transitions for most cases. Kurucz obtained the $f$-values using semi-empirical atomic structure calculations including some relativistic effects (his $f$-values quoted in table 4(a) are statistically averaged over the fine structure).

For most cases the present values agree within $10 \%$ with those by Kurucz. Overall we find that the present $L S$ multiplet oscillator strengths are in somewhat better agreement with the experimental values than those of Kurucz for most transitions (this $i$ also true of the fine structure $f$-values discussed in the next section). 
Table 3. Comparison of calculated (cal) energies (in Ry) of the octet, sextet, quartet and doublet states of Fe II with the observed (obs) ones. * denotes that the observed $L S$ energy is obtained from incomplete set of fine structure levels The table contains the most recent measured values of the energy levels at Lund (Johansson 1992).

\begin{tabular}{|c|c|c|c|c|c|c|c|}
\hline \multirow[b]{2}{*}{ State } & & \multicolumn{2}{|c|}{$E(R y)$} & \multirow[b]{2}{*}{ State } & & \multicolumn{2}{|c|}{$E(\mathrm{Ry})$} \\
\hline & & Ots. & Calc. & & & Obs. & Calc. \\
\hline \multicolumn{8}{|c|}{ Octets: 2-cc } \\
\hline $\begin{array}{l}3 d^{56} S 4 s 4 p^{3} p^{0} \\
3 d^{5} 4 p^{2}\end{array}$ & $\begin{array}{l}z^{8} \mathrm{P}^{0} \\
{ }^{8} \mathrm{P}\end{array}$ & $\begin{array}{l}0.70972 \\
0.21567\end{array}$ & $\begin{array}{l}0.7783 \\
0.2742\end{array}$ & $\begin{array}{l}3 d^{5} 4 s^{7} S 5 s \\
3 d^{5} 4 s^{7} S 4 d\end{array}$ & $\begin{array}{l}{ }^{8} \mathrm{~S} \\
{ }^{8} \mathrm{D}\end{array}$ & $\begin{array}{l}0.25023 \\
0.19213\end{array}$ & $\begin{array}{l}0.2457 \\
0.2300\end{array}$ \\
\hline \multicolumn{8}{|c|}{ Sextets: $21-\mathrm{Cc}$} \\
\hline 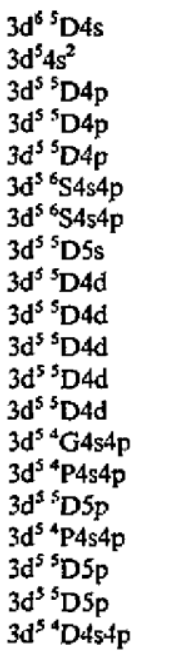 & $\begin{array}{l}a^{6} \mathrm{D} \\
\mathrm{a}^{6} \mathrm{~S} \\
z^{6} \mathrm{D}^{0} \\
z^{6} \mathrm{~F}^{0} \\
z^{6} \mathrm{P}^{0} \\
y^{6} \mathrm{p}^{0} \\
x^{6} \mathrm{P}^{\circ} \\
e^{6} \mathrm{D} \\
\mathrm{e}^{6} \mathrm{~F} \\
{ }^{6} \mathrm{D} \\
{ }^{6} \mathrm{P} \\
\mathrm{e}^{6} \mathrm{G} \\
{ }^{6} \mathrm{~S} \\
\mathrm{y}^{6} \mathrm{~F}^{\circ} \\
{ }^{6} \mathrm{D}_{\mathrm{a}} \\
{ }^{6} \mathrm{D}^{\circ} \\
{ }^{6} \mathrm{p}^{0} \\
{ }^{6} \mathrm{~F}^{0} \\
{ }^{6} \mathrm{P}^{0} \\
{ }^{6} \mathrm{~F}^{\circ}\end{array}$ & $\begin{array}{l}1.18591 \\
0.97721 \\
0.83695 \\
0.80542 \\
0.79726 \\
0.62392 \\
0.46709 \\
0.47640 \\
0.42350 \\
0.42604 \\
0.42130 \\
0.42021 \\
0.41061 \\
0.39240 \\
0.38557 \\
0.37896 \\
0.37553 \\
0.36766 \\
0.35631 \\
0.34940\end{array}$ & $\begin{array}{l}1.1782 \\
0.9951 \\
0.8466 \\
0.8177 \\
0.8111 \\
0.6594 \\
0.4785 \\
0.4687 \\
0.4312 \\
0.4273 \\
0.4219 \\
0.4223 \\
0.4128 \\
0.3756 \\
0.4120 \\
0.3789 \\
0.3966 \\
0.3675 \\
0.3581 \\
0.3756\end{array}$ & $\begin{array}{l}3 d^{54} D 4 s 4 p \\
3 d^{5}{ }^{4} D 4 s 4 p \\
3 d^{55} D 6 s \\
3 d^{55} D 5 d \\
3 d^{55} D 5 d \\
3 d^{55} D 5 d \\
3 d^{55} D 5 d \\
3 d^{55} D 5 d \\
3 d^{5} 4 p^{2} \\
3 d^{5} 4 s^{7} S 5 s \\
3 d^{54} F 4 s 4 p \\
3 d^{55} D 6 p \\
3 d^{55} D 6 p \\
3 d^{55} D 6 p \\
3 d^{54} F 4 s 4 p \\
3 d^{55} D 7 s \\
3 d^{55} D 6 d \\
3 d^{5}{ }^{5} D 6 d \\
3 d^{5} 4 p^{2} \\
3 d^{5} 4 s^{7} S 4 d\end{array}$ & $\begin{array}{l}{ }^{6} \mathrm{D}^{\circ} \\
{ }^{6} \mathrm{P}^{\circ} \\
{ }^{6} \mathrm{D} \\
{ }^{6} \mathrm{~F} \\
{ }^{6} \mathrm{P} \\
{ }^{6} \mathrm{D} \\
{ }^{6} \mathrm{G} \\
{ }^{6} \mathrm{~S} \\
{ }^{6} \mathrm{D} \\
{ }^{6} \mathrm{~S} \\
{ }^{6} \mathrm{~F}^{\circ} \\
{ }^{6} \mathrm{D}^{\circ} \\
{ }^{6} \mathrm{~F}^{\circ} \\
{ }^{6} \mathrm{P}^{\circ} \\
{ }^{6} \mathrm{D}^{\circ} \\
{ }^{6} \mathrm{D} \\
{ }^{6} \mathrm{~F} \\
{ }^{6} \mathrm{G} \\
{ }^{6} \mathrm{P} \\
{ }^{6} \mathrm{D}\end{array}$ & $\begin{array}{l}0.33345 \\
0.32751 \\
0.25937 \\
0.24042^{*} \\
0.23987 \\
0.23633 \\
0.23492 \\
0.22638 \\
0.21862 \\
0.21835 \\
0.21856 \\
0.21765 \\
0.21207 \\
0.21058 \\
0.20451 \\
0.16227 \\
0.15354^{*} \\
0.15148^{*} \\
0.14166 \\
0.12955\end{array}$ & $\begin{array}{l}0.3478 \\
0.3443 \\
0.2555 \\
0.2454 \\
0.2438 \\
0.2422 \\
0.2417 \\
0.2388 \\
0.2713 \\
0.2117 \\
0.2275 \\
0.2197 \\
0.2146 \\
0.2126 \\
0.2116 \\
0.1638 \\
0.1568 \\
0.1550 \\
0.1834 \\
0.1446\end{array}$ \\
\hline \multicolumn{8}{|c|}{ Quartets: $58-c c$} \\
\hline 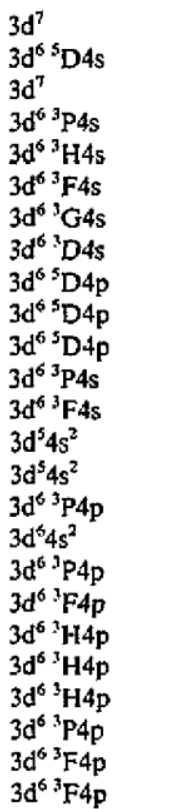 & $\begin{array}{l}a^{4} F \\
a^{4} D \\
a^{4} P \\
b^{4} p \\
a^{4} H \\
b^{4} F \\
a^{4} G \\
b^{4} D \\
z^{4} F^{0} \\
z^{4} D^{\circ} \\
z^{4} P^{0} \\
c^{6} P \\
c^{4} F \\
b^{4} G \\
d^{4} P \\
z^{4} S^{0} \\
c^{4} D \\
y^{4} P^{0} \\
y^{4} F^{\circ} \\
z^{4} G^{\circ} \\
z^{4} H^{\circ} \\
z^{4} I^{\circ} \\
y^{4} D^{0} \\
x^{4} D^{\circ} \\
y^{2} G^{\circ}\end{array}$ & $\begin{array}{l}1.16768 \\
1.11388 \\
1.06566 \\
0.99450 \\
0.99415 \\
0.98186 \\
0.95495 \\
0.90338 \\
0.78223 \\
0.78197 \\
0.75942 \\
0.73596 \\
0.73269 \\
0.69523 \\
0.66603 \\
0.64601 \\
0.63958 \\
0.63549 \\
0.62342 \\
0.63548 \\
0.63434 \\
0.62942 \\
0.62132 \\
0.61370 \\
0.60678\end{array}$ & $\begin{array}{l}1.081 \\
1.1060 \\
0.9846 \\
0.9313 \\
0.9631 \\
0.9327 \\
0.9168 \\
0.8499 \\
0.7968 \\
0.7890 \\
0.7706 \\
0.6515 \\
0.6462 \\
0.6913 \\
0.6331 \\
0.6075 \\
0.6191 \\
0.5997 \\
0.5947 \\
0.6168 \\
0.6193 \\
0.6194 \\
0.5896 \\
0.5857 \\
0.5844\end{array}$ & 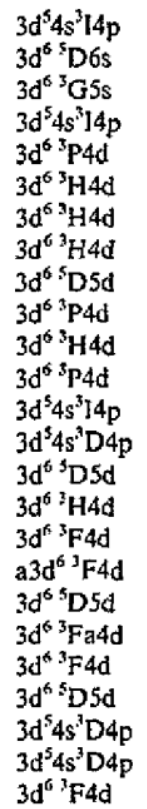 & $\begin{array}{l}{ }^{4} \mathrm{~K}^{\circ} \\
{ }^{4} \mathrm{D} \\
\mathrm{f}^{4} \mathrm{G} \\
{ }^{4} \mathrm{~J}^{\circ} \\
{ }^{4} \mathrm{D} \\
{ }^{4} \mathrm{~K} \\
{ }^{4} \mathrm{H} \\
{ }^{4} \mathrm{G} \\
{ }^{4} \mathrm{~F} \\
{ }^{4} \mathrm{~F} \\
{ }^{4} \mathrm{I} \\
{ }^{4} \mathrm{P} \\
{ }^{4} \mathrm{H}^{\circ} \\
{ }^{4} \mathrm{~F}^{\circ} \\
{ }^{4} \mathrm{D} \\
{ }^{4} \mathrm{~F} \\
{ }^{4} \mathrm{D} \\
{ }^{4} \mathrm{G} \\
{ }^{4} \mathrm{G} \\
{ }^{4} \mathrm{H} \\
{ }^{4} \mathrm{~F} \\
{ }^{4} \mathrm{P} \\
{ }^{4} \mathrm{D}^{\circ} \\
{ }^{4} \mathrm{P}^{\circ} \\
{ }^{4} \mathrm{~F}\end{array}$ & $\begin{array}{l}0.25488 \\
0.25338 \\
0.25241 \\
0.25027 \\
0.24970^{*} \\
0.24407^{*} \\
0.24399 \\
0.24387 \\
0.24320 \\
0.24256 \\
0.24146 \\
0.23441 \\
0.23439 \\
0.23314 \\
0.23253^{*} \\
0.23240^{*} \\
0.23106^{*} \\
0.23107 \\
0.23088 \\
0.22898 \\
0.21664 \\
0.21510 \\
0.21354 \\
0.21916^{*} \\
0.21661\end{array}$ & $\begin{array}{l}0.2852 \\
0.2531 \\
0.2403 \\
0.2810 \\
0.2206 \\
0.2120 \\
0.2104 \\
0.2112 \\
0.2377 \\
0.2188 \\
0.2106 \\
0.2206 \\
0.2606 \\
0.2367 \\
0.2404 \\
0.2007 \\
0.1940 \\
0.1946 \\
0.2389 \\
0.1939 \\
0.1875 \\
0.2267 \\
0.2129 \\
0.2129 \\
0.1875\end{array}$ \\
\hline
\end{tabular}


Table 3. (continued)

\begin{tabular}{|c|c|c|c|c|c|c|c|}
\hline \multirow[b]{2}{*}{ State } & & \multicolumn{2}{|c|}{$E(\mathrm{Ry})$} & \multirow[b]{2}{*}{ State } & & \multicolumn{2}{|c|}{$E(\mathrm{Ry})$} \\
\hline & & Obs. & Calc. & & & Obs. & Calc. \\
\hline $3 d^{63} G 4 p$ & $x^{4} G^{0}$ & 0.59033 & 0.5723 & $3 d^{65} D 6 p$ & ${ }^{4} D^{\circ}$ & $0.21308^{*}$ & 0.2101 \\
\hline $3 d^{63} G 4 p$ & $x^{4} F^{0}$ & 0.58542 & 0.5645 & $3 d^{65} D 6 p$ & ${ }^{4} F^{n}$ & 0.21278 & 0.2133 \\
\hline $3 d^{6}{ }^{3} \mathrm{G} 4 \mathrm{p}$ & $\mathrm{y}^{4} \mathrm{H}^{0}$ & 0.58358 & 0.5669 & $3 d^{65} D 6 p$ & ${ }^{4} \mathrm{P}^{0}$ & 0.20937 & 0.2101 \\
\hline $3 d^{5} 4 s^{5} S 4 p$ & $\mathrm{x}^{4} \mathrm{P}^{0}$ & 0.55889 & 0.5729 & $3 d^{5} 4 s^{3} F 4 p$ & ${ }^{4} G^{0}$ & $0.20868^{*}$ & 0.2115 \\
\hline $3 d^{63} D 4 p$ & $\mathbf{w}^{4} \mathbf{p}^{\circ}$ & 0.53329 & 0.5009 & $3 d^{5} 4 s^{3} F 4 p$ & ${ }^{4} D^{\circ}$ & $0.20248^{*}$ & 0.1984 \\
\hline $3 d^{63} \mathrm{D} 4 \mathrm{p}$ & $w^{4} F^{\circ}$ & 0.52987 & 0.5007 & $3 \mathrm{~d}^{6}{ }^{3} \mathrm{P} 5 \mathrm{p}$ & ${ }^{4} S^{\circ}$ & 0.20214 & 0.1919 \\
\hline $3 d^{63} D 4 p$ & $w^{4} D^{0}$ & 0.52817 & 0.4962 & $3 d^{63} G 4 d$ & ${ }^{8} G$ & 0.20197 & 0.1830 \\
\hline $3 d^{5} 4 s^{2}$ & ${ }^{4} \mathrm{~F}$ & 0.52031 & 0.4884 & $3 d^{63} G 4 d$ & ${ }^{4} \mathrm{H}$ & 0.20181 & 0.1830 \\
\hline $3 d^{65} \mathrm{D} 5 \mathrm{~s}$ & $e^{4} D$ & 0.46240 & 0.4555 & $3 d^{5} 4 s^{3} F 4 p$ & ${ }^{4} F^{\circ}$ & 0.20141 & 0.2022 \\
\hline $3 d^{65} D 4 d$ & $\mathrm{f}^{4} \mathrm{D}$ & 0.41638 & 0.4225 & $3 \mathrm{~d}^{5} 4 \mathrm{~s}^{3} \mathrm{G} 4 \mathrm{p}$ & ${ }^{4} G^{0}$ & 0.20038 & 0.1948 \\
\hline $3 d^{65} D 4 d$ & $e^{4} G$ & 0.41310 & 0.4195 & $3 d^{63} \mathrm{G} 4 \mathrm{~d}$ & ${ }^{4} \mathrm{~J}$ & 0.20019 & 0.1812 \\
\hline $3 d^{65} D 4 d$ & ${ }^{4} S$ & 0.40848 & 0.4142 & $3 d^{63} G 4 d$ & ${ }^{4} \mathrm{D}$ & 0.20003 & 0.1808 \\
\hline $3 d^{65} D 4 d$ & $\mathrm{e}^{4} \mathrm{~F}$ & 0.40242 & 0.3933 & $3 \mathrm{~d}^{6.3} \mathrm{D} 5 \mathrm{~s}$ & ${ }^{4} \mathrm{D}$ & 0.19884 & 0.1860 \\
\hline $3 d^{6}{ }^{3} P 4 p$ & $v^{4} D^{\circ}$ & 0.39918 & 0.3401 & $3 d^{3} 64 s^{3} G 4 p$ & ${ }^{4} \mathbf{H}^{\circ}$ & 0.19810 & 0.2010 \\
\hline $3 d^{65} D 4 d$ & ${ }^{4} \mathrm{P}$ & 0.38709 & 0.3747 & $3 d^{63} P 5 p$ & ${ }^{4} p^{0}$ & 0.19511 & 0.1868 \\
\hline$b 3 d^{63} F 4 p$ & ${ }^{4} G^{\circ}$ & 0.36944 & 0.3475 & $3 d^{63} H 5 p$ & ${ }^{4} \mathrm{I}^{\circ}$ & 0.19004 & 0.1751 \\
\hline $3 d^{63} P 4 p$ & ${ }^{4} \mathrm{~S}^{0}$ & 0.36382 & 0.3144 & $3 d^{63} H 5 p$ & ${ }^{4} G^{\circ}$ & 0.18833 & 0.1588 \\
\hline $3 d^{65} D 5 p$ & ${ }^{4} \mathrm{D}^{\circ}$ & 0.36336 & 0.3631 & $3 d^{6}{ }^{3} \mathrm{P} 5 \mathrm{p}$ & ${ }^{4} D^{\circ}$ & $0.18767^{*}$ & 0.1802 \\
\hline $3 d^{65} D 5 p$ & ${ }^{4} F^{\circ}$ & 0.36261 & 0.3654 & $3 d^{6}{ }^{3} \mathrm{G} 4 \mathrm{~d}$ & ${ }^{4} F$ & 0.18585 & 0.1695 \\
\hline $3 d^{65} D 5 p$ & ${ }^{4} p^{\circ}$ & 0.355 t8 & 0.3575 & $3 d^{63} F 5 p$ & ${ }^{4} F^{0}$ & 0.18529 & 0.1664 \\
\hline $3 d^{6}{ }^{3} \mathrm{P} 4 \mathrm{p}$ & ${ }^{4} p^{\circ}$ & 0.35519 & 0.3348 & $3 d^{5} 4 s^{3} G 4 p$ & ${ }^{4} \mathrm{H}^{\circ}$ & $0.18413^{*}$ & 0.1380 \\
\hline $3 d^{5} 4 s^{5} G 4 p$ & $\mathrm{x}^{4} \mathrm{H}^{0}$ & 0.34980 & 0.3693 & $3 \mathrm{~d}^{64} \mathrm{~F} 5 \mathrm{p}$ & ${ }^{4} D^{\circ}$ & $0.18237^{*}$ & 0.1537 \\
\hline $3 d^{5} 4 s^{5} G 4 p$ & $v^{4} F^{\circ}$ & 0.34810 & 0.3618 & $3 d^{63} H 5 p$ & ${ }^{4} \mathrm{H}^{\circ}$ & 0.17227 & 0.1821 \\
\hline $3 d^{63} F 4 p$ & ${ }^{4} \mathrm{D}^{\circ}$ & 0.34316 & 0.3100 & $3 d^{63} F 5 p$ & ${ }^{\circ} \mathrm{G}^{\circ}$ & 0.16926 & 0.1498 \\
\hline $3 d^{63} F 4 p$ & $u^{4} F^{\circ}$ & 0.33817 & 0.2981 & $3 d^{5} 4 s^{3} H^{4} p$ & ${ }^{4} \mathrm{I}^{\circ}$ & $0.16756^{*}$ & 0.1444 \\
\hline $3 d^{5} 4 s^{5} G 4 p$ & $w^{4} G^{0}$ & 0.33203 & 0.3085 & $3 d^{63} \mathrm{Gsp}$ & ${ }^{4} \mathrm{~F}^{0}$ & 0.16697 & 0.1575 \\
\hline $3 d^{5} 4 s^{5} P 4 p$ & ${ }^{4} \mathrm{P}^{\circ}$ & 0.32856 & 0.2877 & $3 d^{3} 4 s^{5} F 4 p$ & ${ }^{4} \mathrm{G}^{0}$ & $0.16594^{*}$ & 0.1777 \\
\hline $3 d^{5} 4 s^{5} P 4 p$ & ${ }^{4} D^{\circ}$ & 0.31457 & 0.2952 & $3 d^{6 s} D 7 s$ & ${ }^{4} \mathrm{D}$ & 0.15833 & 0.1614 \\
\hline $3 d^{63} P 5 s$ & ${ }^{4} \mathrm{P}$ & 0.29695 & 0.2832 & $3 d^{65}$ D $6 d$ & ${ }^{4} \mathrm{~F}$ & $0.14940^{*}$ & 0.1396 \\
\hline $3 \mathrm{~d}^{63} \mathrm{H} 5 \mathrm{~s}$ & $\mathrm{e}^{4} \mathrm{H}$ & 0.29368 & 0.2404 & $3 \mathrm{~d}^{6}{ }^{3} \mathrm{G} 5 \mathrm{p}$ & ${ }^{4} \mathrm{H}^{\circ}$ & $0.14892^{*}$ & 0.1455 \\
\hline $3 d^{5} 4 s^{5} P 4 p$ & ${ }^{4} S^{0}$ & 0.29358 & 0.2718 & $3 d^{65} D 6 d$ & ${ }^{4} G$ & 0.14662 & 0.1538 \\
\hline $3 d^{5} 4 s^{5} D 4 p$ & ${ }^{4} \mathrm{~F}^{\circ}$ & 0.29237 & 0.2822 & $3 d^{63} G 5 p$ & ${ }^{4} \mathrm{G}^{0}$ & $0.14292^{*}$ & 0.1402 \\
\hline $3 d^{5} 4 s^{5} D 4 p$ & ${ }^{4} \mathrm{D}^{\circ}$ & 0.29153 & 0.2782 & $3 d^{63} D 4 d$ & ${ }^{4} \mathrm{~F}$ & $0.14146^{*}$ & 0.1158 \\
\hline $3 d^{63} F 5 s$ & $\mathrm{f}^{4} \mathrm{~F}$ & 0.21808 & 0.2401 & $3 d^{5} 4 p^{2}$ & ${ }^{4} \mathrm{P}$ & $0.11286^{*}$ & 0.1231 \\
\hline $3 d^{5} 4 s^{5} D 4 p$ & ${ }^{4} \mathrm{P}^{\circ}$ & 0.26375 & 0.2558 & & & & \\
\hline \multicolumn{8}{|c|}{ Doublets: $62-\mathrm{Cc}$} \\
\hline $3 d^{7}$ & $a^{2} G$ & 1.04319 & 0.9380 & $3 d^{5} b^{3} p 4 p$ & $u^{2} D^{\circ}$ & 0.34674 & 0.2851 \\
\hline $3 d^{7}$ & $a^{2} p$ & 1.02079 & 0.9148 & $3 d^{6} b^{3} F 4 p$ & ${ }^{2} \mathrm{D}^{\circ}$ & $0.32672^{*}$ & 0.2698 \\
\hline $3 d^{7}$ & $a^{2} H$ & 1.00242 & 0.9222 & $3 d^{6} b^{3} P 4 p$ & ${ }^{2} \mathrm{P}^{0}$ & $0.32364^{*}$ & 0.2902 \\
\hline $3 d^{7}$ & $a^{2} D$ & 0.99985 & 0.8896 & $3 d^{6} b^{3} F 4 p$ & ${ }^{2} \mathrm{~F}^{\circ}$ & 0.32340 & 0.3180 \\
\hline $3 d^{6} a^{3} P 4 s$ & $\mathrm{~b}^{2} \mathrm{P}$ & 0.95123 & 0.8763 & $3 d^{5} 4 s^{3} G 4 p$ & ${ }^{2} \mathrm{H}^{\circ}$ & 0.31358 & 0.3181 \\
\hline $3 \mathrm{~d}^{6 / 3} \mathrm{H} 4 \mathrm{~s}$ & $\mathrm{~b}^{2} \mathrm{H}$ & 0.95046 & 0.8958 & $3 d^{5} 4 s^{3} G 4 p$ & ${ }^{2} \mathrm{~F}^{0}$ & 0.31193 & 0.2582 \\
\hline $3 d^{6} a^{3} F 4 s$ & $a^{2} F$ & 0.93960 & 0.8905 & $3 d^{5} 4 s^{3} P 4 p$ & ${ }^{2} \mathrm{P}^{\circ}$ & $0.30280^{*}$ & 0.2533 \\
\hline $3 d^{63} \mathrm{G} 4 \mathrm{~s}$ & $b^{2} G$ & $0.91+26$ & 0.8667 & $3 d^{t} b^{t} G 4 p$ & ${ }^{2} \mathrm{H}^{0}$ & 0.29589 & 0.2394 \\
\hline $3 d^{7}$ & $\mathrm{~b}^{2} \mathrm{~F}$ & 0.89883 & 0.7842 & $3 d^{6} b^{1} G 4 p$ & ${ }^{2} \mathrm{~F}^{0}$ & $0.28847^{*}$ & 0.2350 \\
\hline $3 d^{6} 14 s$ & $a^{2} I$ & 0.88997 & 0.8470 & $3 d^{6}{ }^{3} \mathrm{HSs}$ & $\mathrm{e}^{2} \mathrm{H}$ & 0.28571 & 0.2324 \\
\hline $3 d^{6} a^{1} G 4 s$ & $c^{2} G$ & 0.88459 & 0.8307 & $3 d^{6}{ }^{3} \mathrm{P} 5 \mathrm{~s}$ & ${ }^{2} \mathrm{P}$ & 0.28433 & 0.2750 \\
\hline $3 \mathrm{~d}^{6 / 5} \mathrm{D} 4 \mathrm{~s}$ & $b^{2} \mathrm{D}$ & 0.85980 & 0.7966 & $3 d^{5} 4 s^{3} G 4 p$ & ${ }^{2} \mathrm{G}^{\circ}$ & 0.28166 & 0.2741 \\
\hline $3 d^{6} a^{1} S 4 s$ & $a^{2} S$ & 0.85046 & 0.7887 & $3 d^{6} b^{1} G 4 p$ & ${ }^{2} \mathrm{G}^{\circ}$ & 0.28044 & 0.2090 \\
\hline $3 d^{6} a^{1} D 4 s$ & $c^{2} d$ & 0.84174 & 0.7565 & $3 d^{5} 4 s^{3} P 4 p$ & ${ }^{2} \mathrm{D}^{\circ}$ & $0.27478^{*}$ & 0.2521 \\
\hline $3 d^{6}{ }^{1} \mathrm{~F} 4 \mathrm{~s}$ & $c^{2} F$ & 0.78035 & 0.6907 & $3 d^{6} a^{3} F 5 s$ & $e^{2} F$ & 0.27294 & 0.2314 \\
\hline $3 d^{7}$ & $d^{2} D$ & 0.75326 & 0.6128 & $3 d^{5} 4 s^{3} D 4 p$ & ${ }^{2} \mathrm{D}^{\circ}$ & 0.25592 & 0.2379 \\
\hline $3 d^{6} b^{3} P 4 s$ & $c^{2} \mathrm{P}$ & 0.69194 & 0.5975 & $3 d^{5} 4 s^{3} D 4 p$ & ${ }^{2} \mathrm{~F}^{0}$ & 0.24883 & 0.2101 \\
\hline $3 d^{6} b^{3} F 4 s$ & $d^{2} F$ & 0.68951 & 0.5997 & $3 \mathrm{~d}^{63} \mathrm{G} 5 \mathrm{~s}$ & $e^{2} G$ & 0.24403 & 0.2310 \\
\hline
\end{tabular}


Table 3. (continued)

\begin{tabular}{|c|c|c|c|c|c|c|c|}
\hline \multirow{2}{*}{ State } & & \multicolumn{2}{|c|}{$E(\mathrm{Ry})$} & \multirow[b]{2}{*}{ State } & & \multicolumn{2}{|c|}{$E(\mathrm{Ry})$} \\
\hline & & Obs. & Calc. & & & Obs. & Calc. \\
\hline $3 d^{6} b^{\prime} G 4 s$ & $d^{2} G$ & 0.65527 & 0.5513 & $3 d^{5} 4 s^{3} P 4 p$ & ${ }^{2} S^{0}$ & 0.24228 & 0.2123 \\
\hline $3 d^{6} a^{3} P 4 p$ & $\mathrm{z}^{2} \mathrm{D}^{\circ}$ & 0.62921 & 0.5944 & $3 \mathrm{~d}^{63} \mathrm{H} 4 \mathrm{~d}$ & ${ }^{2} \mathrm{~K}$ & 0.24006 & 0.2092 \\
\hline $3 \mathrm{~d}^{63} \mathrm{H} 4 \mathrm{p}$ & $z^{2} G^{\circ}$ & 0.62299 & 0.6072 & $3 d^{65} H 4 d$ & ${ }^{2} \mathrm{~F}$ & 0.23866 & 0.2066 \\
\hline $3 d^{63} \mathrm{H} 4 \mathrm{p}$ & $z^{z} I^{\circ}$ & 0.62049 & 0.5575 & $3 \mathrm{~d}^{63} \mathrm{H} 4 \mathrm{~d}$ & ${ }^{2} G$ & 0.23335 & 0.2008 \\
\hline $3 d^{6} a^{3} F 4 p$ & $z^{2} F^{0}$ & 0.60334 & 0.5794 & $3 \mathrm{~d}^{63} \mathrm{H} 4 \mathrm{~d}$ & ${ }^{2} I$ & 0.23571 & 0.2061 \\
\hline $3 d^{6} a^{3} P 4 p$ & $z^{2} P^{0}$ & 0.59897 & 0.5633 & $3 d^{6.3} P 4 d$ & ${ }^{2} p$ & 0.23174 & 0.2095 \\
\hline $3 d^{6} a^{3} F 4 p$ & $y^{2} G^{\circ}$ & 0.59778 & 0.5713 & $3 d^{63} P 4 d$ & ${ }^{2} \mathrm{D}$ & $0.23069^{*}$ & 0.2108 \\
\hline $3 \mathrm{~d}^{63} \mathrm{H} 4 \mathrm{p}$ & $z^{2} \mathrm{H}^{\circ}$ & 0.59326 & 0.5772 & $3 d^{6} a^{3} F 4 d$ & ${ }^{2} \mathrm{H}$ & 0.22486 & 0.1917 \\
\hline $3 d^{6} a^{3} P 4 p$ & $z^{2} S^{0}$ & 0.58600 & 0.5491 & $3 \mathrm{~d}^{63} \mathrm{H} 4 \mathrm{~d}$ & ${ }^{2} \mathrm{H}$ & 0.22313 & 0.1896 \\
\hline $3 d^{6} a^{3} F 4 p$ & $y^{2} D^{0}$ & 0.57815 & 0.5498 & $3 d^{6} a^{3} F 4 d$ & ${ }^{2} \mathrm{~F}$ & $0.22186^{*}$ & 0.1920 \\
\hline $3 d^{63} G 4 p$ & $\mathrm{y}^{2} \mathrm{H}^{\circ}$ & 0.57244 & 0.5581 & $3 \mathrm{~d}^{5} 4 \mathrm{~s}^{3} \mathrm{D} 4 \mathrm{p}$ & ${ }^{2} \mathrm{P}^{0}$ & 0.22047 & 0.2001 \\
\hline $3 d^{63} G 4 p$ & $y^{2} F^{\circ}$ & 0.55523 & 0.5278 & $3 d^{6} 4 s^{3} I 4 p$ & ${ }^{2} \mathrm{~K}^{0}$ & 0.22043 & 0.2409 \\
\hline $3 d^{63} G 4 p$ & $x^{2} G^{\circ}$ & 0.54810 & 0.5262 & $3 d^{6} 4 s^{3} I 4 p$ & ${ }^{2} \mathrm{H}^{\circ}$ & 0.21616 & 0.2158 \\
\hline $3 d^{61} 14 p$ & $z^{2} \mathrm{~K}^{0}$ & 0.54065 & 0.5211 & $3 \mathrm{~d}^{6} \mathrm{a}^{3} \mathrm{~F} 4 \mathrm{~d}$ & ${ }^{2} G$ & 0.21543 & 0.1849 \\
\hline $3 d^{6} a^{1} G 4 p$ & $x^{2} H^{\circ}$ & 0.53175 & 0.5012 & $3 d^{6} a^{3} F 4 d$ & ${ }^{2} D$ & 0.21085 & 0.1754 \\
\hline $3 d^{6} a^{1} G 4 p$ & $x^{2} F^{n}$ & 0.52418 & 0.4907 & $3 d^{5} a^{3} F 4 d$ & ${ }^{2} \mathrm{P}$ & $0.20457^{*}$ & 0.1648 \\
\hline $3 d^{6} a^{1} G 4 p$ & $w^{2} G^{0}$ & 0.52343 & 0.4883 & $3 d^{61} 15 s$ & ${ }^{2} I$ & 0.19970 & 0.1374 \\
\hline $3 d^{63} D 4 p$ & $y^{2} P^{0}$ & 0.52276 & 0.4852 & $3 d^{6}{ }^{3} \mathrm{P} 5 p$ & ${ }^{2} \mathrm{D}^{\circ}$ & $0.19703^{*}$ & 0.1840 \\
\hline $3 d^{6} 14 p$ & $w^{2} \mathrm{H}^{\circ}$ & 0.51836 & 0.4880 & $3 d^{63} G 4 d$ & ${ }^{2} I$ & 0.19454 & 0.1786 \\
\hline $3 d^{61} 14 p$ & $y^{2} r^{0}$ & 0.51565 & 0.4927 & $3 d^{5} 4 s^{3} 14 p$ & ${ }^{2} \chi^{\circ}$ & 0.19454 & 0.2054 \\
\hline $3 d^{6}{ }^{3} D 4 p$ & $x^{2} D^{\circ}$ & 0.51023 & 0.4747 & $3 d^{6}{ }^{3} D 5 s$ & ${ }^{2} \mathrm{D}$ & 0.19066 & 0.1316 \\
\hline $3 d^{65} D 4 p$ & $w^{2} F^{\circ}$ & 0.49955 & 0.4606 & $3 d^{63} G 4 d$ & ${ }^{2} G$ & 0.18960 & 0.1638 \\
\hline $3 d^{6} a^{\prime} S 4 p$ & $x^{2} P^{0}$ & 0.49460 & 0.4429 & $3 d^{6}{ }^{3} G 4 d$ & ${ }^{2} \mathrm{H}$ & 0.18885 & 0.1625 \\
\hline $3 d^{5} 4 s^{2}$ & ${ }^{2} \mathrm{H}$ & $0.48592^{*}$ & 0.4588 & $3 d^{6}{ }^{3} \mathrm{H} 5 p$ & ${ }^{2} G^{0}$ & 0.18530 & 0.1452 \\
\hline $3 d^{6} a^{1} D 4 p$ & $v^{2} F^{\circ}$ & 0.47920 & 0.4212 & $3 d^{63} G 4 d$ & ${ }^{2} \mathrm{D}$ & 0.18526 & 0.1646 \\
\hline $3 d^{5} 4 s^{2}$ & ${ }^{2} \mathrm{G}$ & 0.47524 & 0.4459 & $3 d^{6}{ }^{3} \mathrm{HSp}$ & ${ }^{2} \mathrm{I}^{\mathrm{o}}$ & 0.18664 & 0.1231 \\
\hline $3 d^{6} a^{1} D 4 p$ & $w^{2} D^{0}$ & 0.47336 & 0.4134 & $3 d^{6}{ }^{3} G 4 d$ & ${ }^{2} \mathrm{~F}$ & 0.18195 & 0.1519 \\
\hline $3 d^{6} a^{1} D 4 p$ & $w^{2} P^{0}$ & 0.46880 & 0.4130 & $3 d^{5} 4 s^{3} F 4 p$ & ${ }^{2} G^{\circ}$ & $0.18128^{*}$ & 0.1823 \\
\hline $3 d^{5} 4 s^{2}$ & ${ }^{2} \mathrm{~F}$ & 0.44525 & 0.4881 & $3 \mathrm{~d}^{63} \mathrm{H} 5 \mathrm{p}$ & ${ }^{2} \mathrm{H}^{\circ}$ & 0.18007 & 0.1370 \\
\hline $3 d^{61} F 4 p$ & $v^{2} G^{\circ}$ & 0.42770 & 0.3710 & $3 d^{63} F 5 p$ & ${ }^{2} G^{0}$ & 0.17293 & 0.1399 \\
\hline $3 d^{6}{ }^{1} F 4 p$ & $v^{2} D^{\circ}$ & 0.42364 & 0.3630 & $3 d^{65} F 5 p$ & ${ }^{2} F^{0}$ & 0.17192 & 0.1417 \\
\hline $3 d^{6} F 4 p$ & $\mathrm{u}^{2} \mathrm{~F}^{\circ}$ & 0.40136 & 0.3411 & $3 d^{63} G 5 p$ & ${ }^{2} \mathbf{H}^{\circ}$ & 0.14510 & 0.1415 \\
\hline $3 d^{6} b^{3} P 4 p$ & ${ }^{2} \mathrm{~S}^{0}$ & 0.37864 & 0.3210 & $3 d^{63} G 5 p$ & ${ }^{2} G^{\circ}$ & $0.14285^{*}$ & 0.1310 \\
\hline $3 d^{6} b^{3} F 4 p$ & $\mathbf{u}^{2} \mathrm{G}^{\circ}$ & 0.34802 & 0.2886 & & & & \\
\hline
\end{tabular}

The comparison needs to be viewed in light of the following: while the present calculations do not explicitly account for the relativistic effects, some allowance is made by using observed energies to obtain the $f$-values with improved accuracy. The electron correlation effects should be better represented in the present work, based on ab initio close coupling calculations, than the semi-empirical method of Kurucz involving fitting of parameters to observed energy levels. For most transitions therefore the present data for Fe II obtained in this manner should be at least as accurate as currently available values. The present results provide an alternative dataset for a large number of oscillator strengths for Fe II, although it is difficult to state the uncertainties precisely. The $L S$ coupling $f$-values given in table $4(a)$ provide an overall indication of the accuracy of the total multiplet strengths in the total dataset,

In table $4(b)$ we further extend the comparisons to the fine structure components, obtained through algebraic transformation (Alien 1976) as described earlier. Only selected oscillator strengths are presented for which a complete or almost complete set of fine structure oscillator strengths is available. 
Table 4. (a) Comparison of oscillator strengths, $f_{i f}$, of Fe II in $L S$ coupling. $\Delta E$ is the transition energy, (b) Comparison of fine structure oscillator strengths for transitions in Fe II. For each transition the first line corresponds to the $L S$ values and the following lines to the fine structure components, (c) Calculated and measured lifetimes, $\tau$, of Fe II levels.

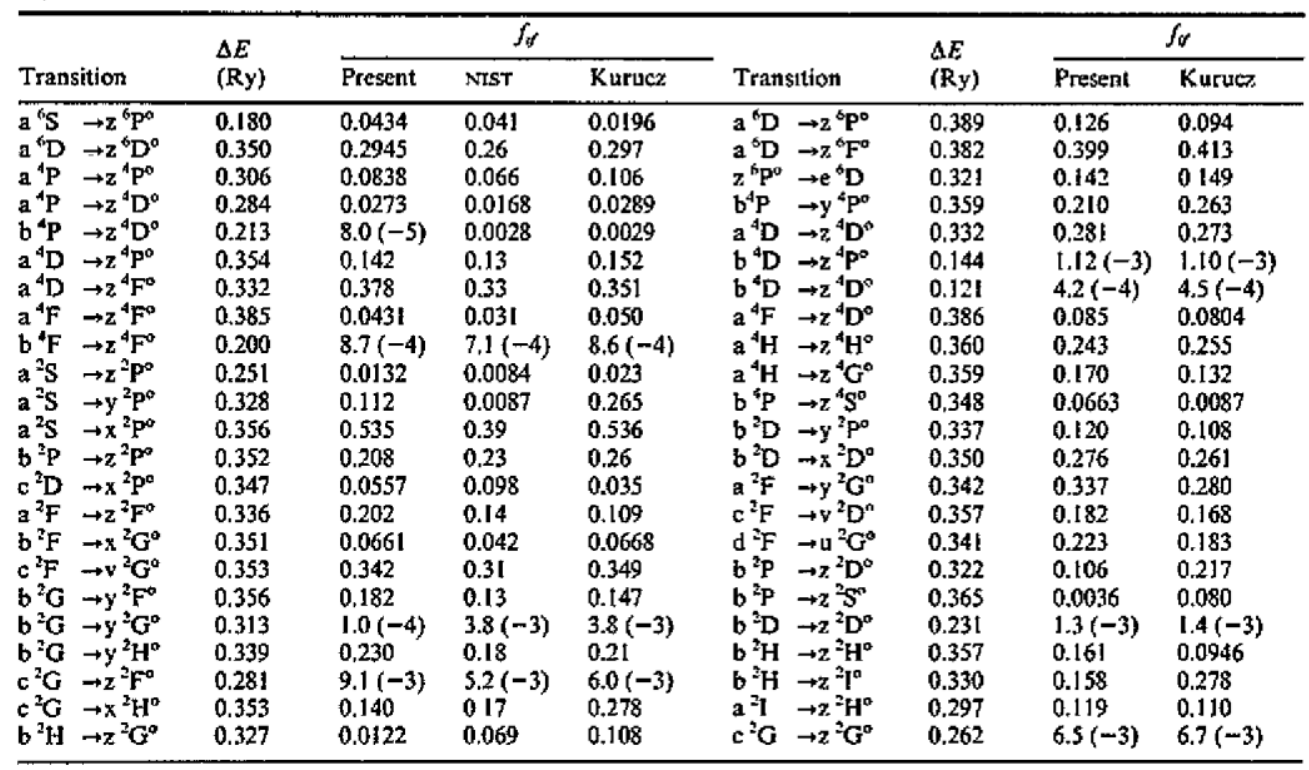

(b)

\begin{tabular}{|c|c|c|c|c|c|c|c|c|c|c|c|c|}
\hline \multirow[b]{2}{*}{ Transition } & \multirow{2}{*}{$\begin{array}{l}\lambda_{U /} \\
\text { (A) }\end{array}$} & \multirow[b]{2}{*}{$g_{i}$} & \multirow[b]{2}{*}{$g_{f}$} & \multicolumn{3}{|c|}{$f_{l y}$} & \multirow{2}{*}{$\begin{array}{l}\lambda_{\sigma} \\
(A)\end{array}$} & \multirow[b]{2}{*}{$g_{1}$} & \multirow[b]{2}{*}{$g$} & \multicolumn{3}{|c|}{$f_{v}$} \\
\hline & & & & Present & NIST & Kurucs. & & & & Present & NIST & Kuruce \\
\hline \multirow[t]{3}{*}{$\mathrm{a}^{6} \mathrm{~S}^{c} \rightarrow \mathrm{z}^{6} \mathrm{p}^{a}$} & & 6 & 18 & 0.0434 & 0.041 & 0.0196 & & & & & & \\
\hline & 5170 & 6 & 8 & 0.0189 & 0.023 & 0.0083 & 4925 & 6 & 4 & 0.0099 & 0.008 & 0.0046 \\
\hline & 5020 & 6 & 6 & 0.0146 & 0.010 & 0.0066 & & & & & & \\
\hline \multirow{6}{*}{$a^{6} D^{e} \rightarrow z^{6} p^{0}$} & & 30 & 18 & 0.126 & & 0.0938 & & & & & & \\
\hline & 2344 & 10 & 8 & 0.126 & 0.11 & 0.129 & 2360 & 4 & 6 & 0.0377 & & 0.0718 \\
\hline & 2366 & 8 & 8 & 0.0449 & 0.051 & 0.0566 & 2328 & 6 & 4 & 0.0396 & 0.032 & 0.039 \\
\hline & 2381 & 6 & 8 & 0.0099 & 0.036 & 0.0392 & 2339 & 4 & 4 & 0.0887 & 0.087 & 0.103 \\
\hline & 2334 & 8 & 6 & 0.0814 & & 0.0805 & 2345 & 2 & 4 & 0.126 & 0.13 & 0.177 \\
\hline & 2349 & 6 & 6 & 0.077 & & 0.094 & & & & & & \\
\hline \multirow[t]{8}{*}{$a^{b} D^{e} \rightarrow z^{6} D^{a}$} & & 30 & 30 & 0.294 & 0.26 & 0.297 & & & & & & \\
\hline & 2600 & 10 & 10 & 0.240 & 0.22 & 0.261 & 2608 & 6 & 4 & 0.118 & 0.11 & 0.133 \\
\hline & 2587 & 10 & 8 & 0.0548 & 0.065 & 0.0766 & 2632 & 4 & 6 & 0.175 & 0.12 & 0.133 \\
\hline & 2636 & 8 & 10 & 0.0675 & 0.043 & 0.0459 & 2621 & 4 & 4 & 0.00322 & 0.0037 & 0,00395 \\
\hline & 2613 & 8 & 8 & 0.131 & 0.11 & 0.135 & 2615 & 4 & 2 & 0.114 & 0.10 & 0.119 \\
\hline & 2599 & 8 & 6 & 0.0948 & 0.099 & 0.117 & 2629 & 2 & 4 & 0.227 & 0.18 & 0.188 \\
\hline & 2632 & 6 & 8 & 0.125 & 0.084 & 0.0887 & 2622 & 2 & 2 & 0.0652 & 0.050 & 0.0587 \\
\hline & 2618 & 6 & 6 & 0.0502 & 0.045 & 0.0517 & & & & & & \\
\hline \multirow{8}{*}{$\mathrm{a} \mathrm{D}^{\mathrm{c}} \rightarrow \mathrm{z}^{\mathrm{e}} \mathrm{F}^{\circ}$} & & 30 & 42 & 0.397 & & 0.413 & & & & & & \\
\hline & 2383 & 10 & 12 & 0.342 & 0.328 & 0.36 & 2400 & 6 & 6 & 0.131 & 0.12 & 0.130 \\
\hline & 2374 & 10 & 10 & 0.0527 & 0.028 & 0.0340 & 2396 & 6 & 4 & 0.0227 & 0.019 & 0.017 \\
\hline & 2368 & 10 & 8 & 0.00425 & & $4.4(-5)$ & 2411 & 4 & 6 & 0.203 & 0.19 & 0.232 \\
\hline & 2396 & 8 & 10 & 0.289 & 0.27 & 0.323 & 2407 & 4 & 4 & 0.161 & 0.14 & 0.167 \\
\hline & 2389 & 8 & 8 & 0.0968 & 0.089 & 0.0924 & 2405 & 4 & 2 & 0.0314 & 0.031 & 0.0290 \\
\hline & 2384 & 8 & 6 & 0.0122 & & 0.0057 & 2414 & 2 & 4 & 0.175 & 0.19 & 0.200 \\
\hline & 2406 & 6 & 8 & 0.243 & 0.20 & 0.265 & 2412 & 2 & 2 & 0.220 & 0.21 & 0.236 \\
\hline \multirow{5}{*}{$\mathrm{a}^{4} \mathrm{P}^{6} \rightarrow \mathrm{z}^{4} \mathrm{P}^{\circ}$} & & 12 & 12 & 0.0838 & 0.066 & 0.106 & & & & & & \\
\hline & 2986 & 6 & 6 & 0.0585 & 0.048 & 0.0763 & 2945 & 4 & 2 & 0.0353 & 0.03 & 0.0452 \\
\hline & 2949 & 6 & 4 & 0.0254 & 0.017 & 0.0327 & 2986 & 2 & 4 & 0.0696 & 0.048 & 0.0843 \\
\hline & 3004 & 4 & 6 & 0.0374 & 0.029 & 0.0427 & 2965 & 2 & 2 & 0.0140 & 0.012 & 0.0169 \\
\hline & 2966 & 4 & 4 & 0.0112 & 0.0079 & 0.0154 & & & & & & \\
\hline \multirow[t]{3}{*}{$\mathrm{a}^{4} \mathbf{P}^{\mathrm{c}} \rightarrow \mathrm{z}^{4} \mathrm{D}^{\circ}$} & & 12 & 20 & 0.0273 & 0.0168 & 0.0289 & & & & & & \\
\hline & 3229 & 6 & 8 & 0.0217 & 0.012 & 0.023 & 3188 & 4 & 4 & 0.00881 & 0.0049 & $0.008: 34$ \\
\hline & 3194 & 6 & 6 & 0.00495 & 0.0019 & 0.00336 & $3[7]$ & 4 & 2 & 0.00139 & $6.9(-4)$ & 0.00116 \\
\hline
\end{tabular}


Table 4. (continued)

\begin{tabular}{|c|c|c|c|c|c|c|c|c|c|c|c|c|}
\hline \multirow[b]{2}{*}{ Transition } & \multirow{2}{*}{$\begin{array}{l}\lambda_{\phi} \\
(A)\end{array}$} & \multirow[b]{2}{*}{$\boldsymbol{g}_{j}$} & \multirow[b]{2}{*}{$g_{f}$} & \multicolumn{3}{|c|}{$f_{V}$} & \multirow{2}{*}{$\begin{array}{l}\lambda_{\psi} \\
(\dot{A})\end{array}$} & \multirow[b]{2}{*}{$g_{1}$} & \multirow[b]{2}{*}{$8 f$} & \multicolumn{3}{|c|}{$f_{1 \prime}$} \\
\hline & & & & Present & NIST & Kurucz & & & & Present & NIST & Kurucz \\
\hline \multirow{6}{*}{$a^{4} D^{c} \rightarrow z^{4} P^{0}$} & $\begin{array}{l}3168 \\
3214\end{array}$ & $\begin{array}{l}6 \\
4\end{array}$ & $\begin{array}{l}4 \\
6\end{array}$ & $\begin{array}{l}5.5(-4) \\
0.0172\end{array}$ & $\begin{array}{l}1.4(-4) \\
0.015\end{array}$ & $\begin{array}{l}2.8(-4) \\
0.0206\end{array}$ & $\begin{array}{l}3211 \\
3195\end{array}$ & $\begin{array}{l}2 \\
2\end{array}$ & $\begin{array}{l}4 \\
2\end{array}$ & $\begin{array}{l}0.0137 \\
0.0137\end{array}$ & $\begin{array}{l}0.0081 \\
0.0095\end{array}$ & $\begin{array}{l}0.0170 \\
0.0153\end{array}$ \\
\hline & & 20 & 12 & 0.142 & 0.13 & 0.152 & & & & & & \\
\hline & 2563 & 8 & 6 & 0.143 & 0.11 & 0.144 & 2583 & 4 & 4 & 0.0754 & 0.077 & 0.0885 \\
\hline & 2592 & 6 & 6 & 0.0423 & 0.052 & 0.055 & 2595 & 2 & 4 & 0.0235 & 0.026 & 0.0306 \\
\hline & 2612 & 4 & 6 & 0.0070 & 0.0093 & 0.011 & 2568 & 4 & 2 & 0.0593 & 0.056 & 0.0604 \\
\hline & 2564 & 6 & 4 & 0,0997 & 0.085 & 0.0995 & 2579 & 2 & 2 & 0.118 & 0.13 & 0.132 \\
\hline \multirow[t]{6}{*}{$a^{4} D^{e} \rightarrow z^{4} D^{\circ}$} & & 20 & 20 & 0.281 & & 0.273 & & & & & & \\
\hline & 2740 & 8 & 8 & 0.241 & 0.22 & 0.268 & 2770 & 4 & 6 & 0.0973 & 0,0077 & 0.0267 \\
\hline & 2715 & 8 & 6 & 0.0404 & 0.045 & 0.05 & 2750 & 4 & 4 & 0.112 & 0.12 & 0.131 \\
\hline & 2774 & 6 & 8 & 0.0528 & $8.0(-5)$ & 0.0049 & 2738 & 4 & 2 & 0.0703 & & 0.0713 \\
\hline & 2748 & 6 & 6 & 0.161 & 0.18 & 0.189 & 2763 & 2 & 4 & 0.139 & 0.026 & 0.0632 \\
\hline & 2728 & 6 & 4 & 0.0659 & 0.063 & 0.0746 & 2750 & 2 & 2 & 0.140 & 0.12 & 0.131 \\
\hline \multirow[t]{5}{*}{$\mathrm{a}^{4} \mathrm{D}^{*} \rightarrow z^{4} \mathrm{~F}^{\circ}$} & & 20 & 28 & 0.378 & 0.33 & 0.351 & & & & & & \\
\hline & $\begin{array}{l}2757 \\
2718\end{array}$ & $\begin{array}{l}8 \\
8\end{array}$ & $\begin{array}{r}10 \\
8\end{array}$ & $\begin{array}{l}0.336 \\
0.0389\end{array}$ & $\begin{array}{l}0.30 \\
0.0011\end{array}$ & $\begin{array}{l}0.266 \\
0.0041\end{array}$ & $\begin{array}{l}2710 \\
2747\end{array}$ & $\begin{array}{l}6 \\
4\end{array}$ & $\begin{array}{l}4 \\
6\end{array}$ & $\begin{array}{l}0.00365 \\
0.303\end{array}$ & $\begin{array}{l}1.9(-4) \\
0.33\end{array}$ & $\begin{array}{l}2.3(-4) \\
0.364\end{array}$ \\
\hline & 2694 & 8 & 6 & 0.00199 & 0.001 & $7.2(-5)$ & 2732 & 4 & 4 & 0.0760 & 0.028 & 0.0485 \\
\hline & 2750 & 6 & 8 & 0.308 & 0.32 & 0,351 & 2744 & 2 & 4 & 0.378 & 0.41 & 0,446 \\
\hline & 2726 & 6 & 6 & 0.0662 & 0.011 & 0.0264 & & & & & & \\
\hline \multirow{6}{*}{$b^{4} D^{6} \rightarrow x^{4} D^{\circ}$} & & 20 & 20 & 0.0223 & & 0.02 & & & & & & \\
\hline & $3 ! 78$ & 8 & 8 & 0,0189 & 0.012 & 0.017 & 3134 & 4 & 6 & 0.00782 & 0.0035 & 0.0037 \\
\hline & 3146 & 8 & 6 & 0.00317 & 0.0023 & 0.0032 & 3115 & 4 & 4 & 0,00899 & 0.0098 & 0.0099 \\
\hline & 3169 & 6 & 8 & 0.0042 & & $5.8(-4)$ & 3106 & 4 & 2 & 0.00564 & 0.0057 & 0.0058 \\
\hline & 3136 & 6 & 6 & 0,0128 & 0.012 & 0.014 & 3116 & 2 & 4 & 0.0112 & 0,0081 & 0.0085 \\
\hline & 3117 & 6 & 4 & 0.00524 & 0.0068 & 0.0058 & 3106 & 2 & 2 & 0.0113 & 0.011 & 0.0108 \\
\hline \multirow{5}{*}{$\mathrm{a}^{4} \mathrm{~F}^{e} \rightarrow \mathrm{z}^{4} \mathrm{D}^{0}$} & & 28 & 20 & 0.0854 & & 0.0804 & & & & & & \\
\hline & 2349 & 10 & 8 & 0.0859 & 0.034 & 0.0794 & 2400 & 4 & 6 & 0.00168 & & 0.0041 \\
\hline & $\begin{array}{l}2380 \\
2403\end{array}$ & $\frac{8}{6}$ & $\begin{array}{l}8 \\
8\end{array}$ & $\begin{array}{l}0.012] \\
8.1(-4)\end{array}$ & $\begin{array}{l}0.13 \\
0.0022\end{array}$ & $\begin{array}{l}0.0257 \\
0.0028\end{array}$ & $\begin{array}{l}2369 \\
2385\end{array}$ & $\begin{array}{l}6 \\
4\end{array}$ & $\begin{array}{l}4 \\
4\end{array}$ & $\begin{array}{l}0.0639 \\
0.0237\end{array}$ & 0.033 & 0.0609 \\
\hline & 2361 & 8 & 6 & 0.0733 & 0.037 & 0.066 & 2376 & 4 & 2 & 0.0595 & 0.041 & 0.0648 \\
\hline & 2384 & 6 & 6 & 0.0206 & 0.029 & 0.035 & & & & & & \\
\hline \multirow[t]{6}{*}{$a^{4} F^{x} \rightarrow z^{4} F^{0}$} & & 28 & 28 & 0.0431 & 0.031 & 0.050 & & & & & & \\
\hline & 2361 & 10 & 10 & 0.0396 & 0.020 & 0.0429 & 2386 & 6 & 8 & 0.00763 & 0.0038 & 0.00657 \\
\hline & 2332 & 10 & 8 & 0.00362 & 0.019 & 0.0206 & 2367 & 6 & 6 & 0.0296 & 0.0084 & 0.0191 \\
\hline & 2392 & 8 & to & 0.00442 & 0.0029 & 0.00504 & 2356 & 6 & 4 & 0.00577 & 0.013 & 0.0150 \\
\hline & 2363 & 8 & 8 & 0,0329 & 0.011 & 0.0227 & 2383 & 4 & 6 & 0.00856 & 0.0051 & 0.00714 \\
\hline & 2345 & 8 & 6 & 0.00583 & 0.018 & 0.0208 & 2371 & 4 & 4 & 0.0344 & 0.012 & 0.0265 \\
\hline \multirow{6}{*}{$\begin{array}{l}a^{2} S^{e} \rightarrow z^{2} p^{\circ} \\
a^{2} S^{c} \rightarrow y^{2} p^{\circ} \\
a^{2} S^{c} \rightarrow x^{2} p^{\circ}\end{array}$} & & 2 & 6 & 0.0132 & 0.0084 & 0,023 & & & & & & \\
\hline & 3622 & 2 & 4 & 0.00878 & $0.005 \mathrm{I}$ & 0.015 & 3626 & 2 & 2 & 0.00438 & 0.0035 & 0.008 \\
\hline & & 2 & 6 & 0.113 & $0.008 \mathrm{~T}$ & 0.265 & & & & & & \\
\hline & 2781 & 2 & 4 & 0.0749 & $0.05 \overline{4}$ & 0.085 & 2781 & 2 & 2 & 0.0374 & 0.034 & 0.18 \\
\hline & & 2 & 6 & 0.535 & 0.39 & 0.536 & & & & & & \\
\hline & 2571 & 2 & 4 & 0.355 & 0.23 & 0.347 & 2541 & 2 & 2 & 0.180 & 0.15 & 0.188 \\
\hline
\end{tabular}

(c)

\begin{tabular}{|c|c|c|c|c|c|c|c|c|c|}
\hline \multirow[b]{2}{*}{ State } & \multirow[b]{2}{*}{$J$} & \multicolumn{3}{|c|}{$\tau(\mathrm{ns})$} & \multirow[b]{2}{*}{ State } & \multirow[b]{2}{*}{$\mathbf{J}$} & \multicolumn{3}{|c|}{$\tau(\mathrm{ns})$} \\
\hline & & Present & Expt & Kurucz & & & Present & Expt & Kurucz \\
\hline$z^{6} \mathrm{P}^{0}$ & $7 / 2$ & 3.884 & $\begin{array}{l}3.73(0.06)^{\mathrm{d}}, 3.8(0.2)^{\mathrm{b}} \\
3.5(0.3)^{\mathrm{c}}, 3.73(0.05)^{\mathrm{d}}\end{array}$ & 3.28 & $\begin{array}{l}z^{6} F^{0} \\
z^{6} F^{6}\end{array}$ & $\begin{array}{l}9 / 2 \\
7 / 2\end{array}$ & $\begin{array}{l}3.024 \\
3.034\end{array}$ & $\begin{array}{l}3.2(0.2)^{\mathrm{b}}, 3.24(6)^{\mathrm{d}} \\
3.26(10)^{\mathrm{d}}\end{array}$ & $\begin{array}{l}2.89 \\
2.92\end{array}$ \\
\hline$x^{6} \mathrm{p}^{a}$ & $5 / 2$ & 3.844 & $\begin{array}{l}3.79(0.12)^{6}, 3.7(0.2)^{b} \\
3.5(0.3)^{2}, 3.83(0.07)^{d}\end{array}$ & 3.26 & $z^{6}{ }^{6} \mathrm{~F}^{\circ}$ & $\begin{array}{l}5 / 2 \\
3 / 2\end{array}$ & $\begin{array}{l}2.973 \\
2.908\end{array}$ & $\begin{array}{l}3.3(0.2)^{c} 3.33(9)^{d} \\
3.3(0.2)^{c}, 3.34(10)^{d}\end{array}$ & $\begin{array}{l}2.93 \\
2.94\end{array}$ \\
\hline$z^{6} p^{0}$ & $3 / 2$ & 3.819 & $\begin{array}{l}3.71(0.12)^{n}, 3.6(0.2)^{b} \\
3.4(0.3)^{\mathrm{c}}\end{array}$ & 3.25 & $z^{6} F^{\circ}$ & $\begin{array}{l}1 / 2 \\
5 / 2\end{array}$ & $\begin{array}{l}2.878 \\
3.250\end{array}$ & $\begin{array}{l}3.3(0.3)^{\mathrm{c}} \\
3.44(0.11)^{\mathrm{n}}\end{array}$ & 2.94 \\
\hline $\begin{array}{l}z^{6} D^{0} \\
z^{6} D^{\circ}\end{array}$ & $\begin{array}{l}9 / 2 \\
7 / 2\end{array}$ & $\begin{array}{l}3.460 \\
3.487\end{array}$ & $\begin{array}{l}3.7(0.2)^{b}, 3.7(0.2)^{c} \\
3.75(20)^{b}, 3.8(0.3)^{c} \\
3.68(0.7)^{d}\end{array}$ & $\begin{array}{l}3,41 \\
3,43\end{array}$ & $\begin{array}{l}z^{4} D^{0} \\
z^{4} D^{0} \\
z^{4} D^{0}\end{array}$ & $\begin{array}{l}7 / 2 \\
5 / 2 \\
3 / 2\end{array}$ & $\begin{array}{l}2.476 \\
2.496 \\
2.494\end{array}$ & $\begin{array}{l}3.02(0.07)^{\mathrm{n}}, 3.1(0.2)^{\mathrm{b}} \\
3.1(0.08)^{\mathrm{n}}, 3.1(0.2)^{\mathrm{b}} \\
3.0(0.2)^{\mathrm{b}}\end{array}$ & $\begin{array}{l}2.43 \\
2.44 \\
2.43\end{array}$ \\
\hline $\mathrm{z}^{6} \mathrm{D}^{\circ}$ & $\begin{array}{l}5 / 2 \\
3 / 2\end{array}$ & $\begin{array}{l}3.406 \\
3.392\end{array}$ & $\begin{array}{l}3.7(0.2)^{\mathrm{h}}, 3.63(8)^{\mathrm{d}} \\
3.7(0.2)^{6}, 3.7(0.2)^{\mathrm{c}} \\
3.83(10)^{\mathrm{d}}\end{array}$ & $\begin{array}{l}3.44 \\
3.45\end{array}$ & $\begin{array}{l}z^{4} D^{\circ} \\
z^{4} F^{0} \\
z^{4} F^{\circ}\end{array}$ & $\begin{array}{l}1 / 2 \\
9 / 2 \\
7 / 2\end{array}$ & $\begin{array}{l}2.498 \\
3.471 \\
3.435\end{array}$ & $\begin{array}{l}2.9(0.2)^{b} \\
3.87(0.09)^{n}, 3.7(0.2)^{b} \\
3.63(0.11)^{n}, 3.6(0.2)^{b}\end{array}$ & $\begin{array}{l}2.42 \\
3.34 \\
3.22\end{array}$ \\
\hline${ }^{5} 0^{0}$ & $1 / 2$ & 3.259 & $\begin{array}{l}3.8(0.2)^{b}, 3.8(0.3)^{c} \\
3.76(10)^{b}\end{array}$ & 3.45 & $\begin{array}{l}z^{4} F^{\circ} \\
z^{4} F^{\circ}\end{array}$ & $\begin{array}{l}5 / 2 \\
3 / 2\end{array}$ & $\begin{array}{l}3.417 \\
3.422\end{array}$ & $\begin{array}{l}3.75(0.14)^{n}, 3.7(0.2)^{b} \\
3.7(0.2)^{b}\end{array}$ & $\begin{array}{l}3.26 \\
3.3\end{array}$ \\
\hline$z^{n} F^{\circ}$ & $11 / 2$ & 2.982 & $\begin{array}{l}3.2(0.2)^{b}, 3.3(0.2)^{c} \\
3.19(4)^{d}\end{array}$ & 2.83 & & & & & \\
\hline
\end{tabular}

Guo er al (1992).

SChade et al (1988).

'Hannaford el al (1992).

${ }^{\circledR}$ Biemont et al (1991). 
There are a few measured values of Fe II that are with low uncertainty, rated B or $<10 \%$. However, most of them are rated with a 50\% uncertainty (D in the NIST compilation). The measured $R$-values of the fine structure transitions of an $L S$ multiplet usually do not correspond to the same experiment, rather to more than one experimental source. Among all the transitions, one complete set that has been rated with $10 \%$ uncertainty is a ${ }^{6} \mathrm{D}^{\mathrm{e}} \rightarrow \mathrm{z}{ }^{6} \mathrm{D}^{\mathrm{o}}$. For this particular multiplet, the component fine structure transitions show about same level of agreement between the present values and the measured ones, as between the Kurucz values and the experimental values. However, overall comparison shows that the present values agree better with the measured values than the Kurucz data set. All the transitions listed in the NIST compilation have been compared, and this provides more detailed information on the uncertainties than the comparison of total $L S$ multiplets. (The wavelengths given in table $4(b)$ are approximate.)

Another interesting comparison may be made between the calculated and observed lifetimes. We calculate the lifetime of a state based on all allowed transitions from the given state, i.e., $\tau_{j}=\left[\Sigma A_{J i}\right]^{-1}$ where $A_{j i}=a^{3} g_{i} / g_{j} E_{j i}^{2} f_{i j} / \tau_{0}$ is the transition probability in $s^{-1}, f_{i j}$ is the oscillator strength, $\tau_{0}$ is the unit of time, and the sum is over all lower i-states that are connected by dipole allowed transitions from the upper state $j$. The lifetimes are calculated using the present fine structure $f$-values. Table $4(c)$ presents the calculated lifetimes and compares with the available measured values, and those from Kurucz. It should be noted that the Kurucz calculations involve forbidden transitions, and hence the lifetimes include both the dipole allowed and forbidden transitions; however the latter contribution is expected to be small for most levels under consideration. Present lifetimes of the fine structure levels of $\mathrm{z}{ }^{6} \mathrm{P}^{\mathrm{o}}$ agree well with the recent measured values of Hannaford et at (3992) and Guo et al (1992), whereas those of Schade et al (1988) are lower than the present values and other measured values. Values obtained by Kurucz are also lower than the present ones in a similar manner. For other states, the agreement between the present values and the experimental ones is better than that of Kurucz. The present values are in general within $5-10 \%$ of the experimental values.

\subsection{Photoionization cross sections}

Photoionization cross sections, including the detailed autoionizing resonances, are calculated for all bound states which include the 743 bound states of Fe II that lie below the first ionization threshold. Selected examples of the cross sections are presented. Figure 1 shows the photoionization cross sections of the $3 \mathrm{~d}^{5} 4 \mathrm{~s}{ }^{6} \mathrm{D}$ ground state of Fe II. As discussed by LeDourneuf et al (1993) the present ground state cross sections are about two orders of magnitude higher than the earlier calculations (Sawey and Berrington 1992) which included only the ground state of Fe III in the target expansion, whereas the dominant contribution stems from the photoionization of the $3 \mathrm{~d}$ shell i.e. through coupling to the excited $3 d^{5} 4 s$ state of Fe III.

Figure 2(a) shows the photoionization cross sections of the lowest three quartet states, $3 d^{7}\left({ }^{4} F\right), 3 d^{6} 4 s\left({ }^{4} \mathrm{D}\right)$ and $3 d^{7}\left({ }^{4} \mathrm{P}\right)$. These metastable states are likely to be of considerable importance in astrophysical plasmas as one expects these to be in local thermodynamic equilibrium (LTE) even at fairly low densities owing to small radiative decay rates. Thus there may be significant populations in the low-lying metastable states, 


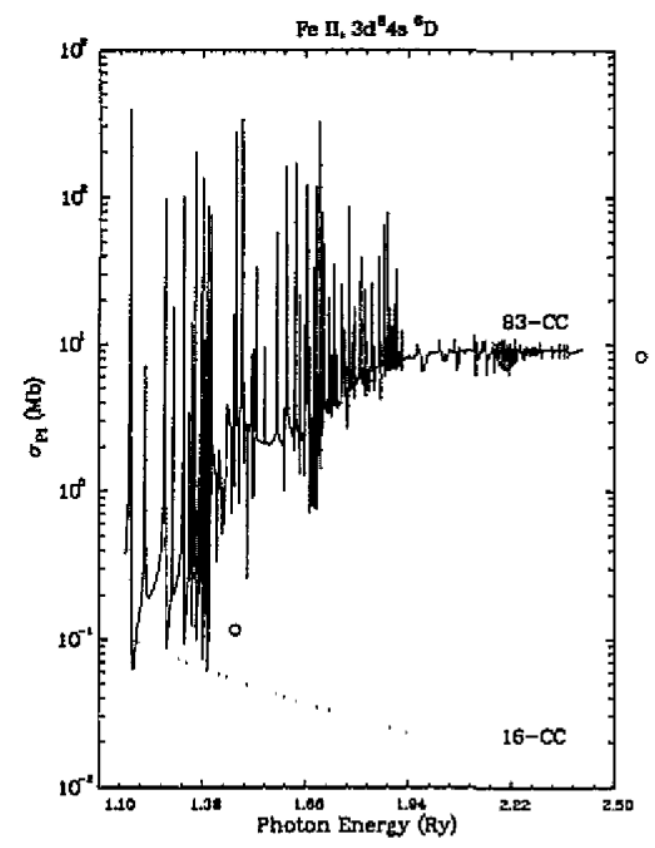

Figure 1. Photoionization cross section of the $3 \mathrm{~d}^{5} 4 \mathrm{~s}^{6} \mathrm{D}$ ground state of Fe II using 83-CC expansion. The dotted curve corresponds to earlier 16-CC calculations (Sawey and Berrington 1992); also shown are the central field cross sections in circles (Reilman and Manson 1979).

comparable to the ground state, in accordance with respective statistical weights. Photoionization models therefore need to consider not only ground state photoionization but also that of at least these three states (other states lie significantly higher and would be relatively less important). Figure 2(b) presents the photoionization cross sections of the three lowest doublet states of Fe II. Extensive resonances can be seen to dominate the metastable states $3 d^{7}{ }^{4} \mathrm{P}$ and $3 d^{72} \mathrm{P}$ for the entire energy range up to the highest target threshold, and resulting in large variations in the background cross sections. Though the background cross sections smooth out at higher energies due to weaker coupling to high target states, all $3 \mathrm{~d}^{7}$ states and $3 \mathrm{~d} 64 \mathrm{~s}{ }^{4} \mathrm{D}$ show significant variations in the cross sections in the near threshold region due to resonances.

Figure 3 presents photoionization cross sections of two octet states, $3 \mathrm{~d}^{5} 4 \mathrm{~s}^{7} \mathrm{~S} 5 \mathrm{~s}{ }^{8} \mathrm{~S}$ and the equivalent electron state $3 \mathrm{~d}^{5} 4 \mathrm{p}^{2}{ }^{8} \mathrm{P}$. Both states show the presence of a large resonance at the threshold, and the repetition of resonance patterns converging on to the ${ }^{7} \mathrm{P}^{0}$ target state. The octet state photoionization cross sections have been obtained for the first time.

Figure 4 consists of eight panels presenting photoionization cross sections of the Rydberg series of states, $3 \mathrm{~d}^{6}{ }^{5} \mathrm{Dnp}{ }^{4} P^{o}$ where $4 \leq n \leq 11$ of Fe II. The figure illustrates the wider photo-excitation of core (PEC) resonances which occur at the energies of the target states $3 d^{56} \mathrm{~S} 4 \mathrm{p}$ $\left({ }^{5} \mathrm{P}^{\circ}\right), 3 \mathrm{~d}^{5}{ }^{4} \mathrm{P} 4 \mathrm{p}\left({ }^{5} \mathrm{P}^{\mathrm{o}}\right), 3 \mathrm{~d}^{5}{ }^{4} \mathrm{D} 4 \mathrm{p}\left({ }^{5} \mathrm{P}^{0}\right), 3 \mathrm{~d}^{5}{ }^{4} \mathrm{~F} 4 \mathrm{p}\left({ }^{5} \mathrm{D}^{\mathrm{o}}\right)$, corresponding to dipole allowed transitions from the ground state ${ }^{5} \mathrm{D}$ (the positions of the PEC resonances are pointed out by arrows in the top panel). At these energies, the outer 'np'electron remains as a spectator while the ground core state $3 d^{5} 4 s{ }^{5} \mathrm{D}$ is excited via strong dipole transitions giving rise to wide resonances in photoionization cross sections (Yu and Seaton 1987). 

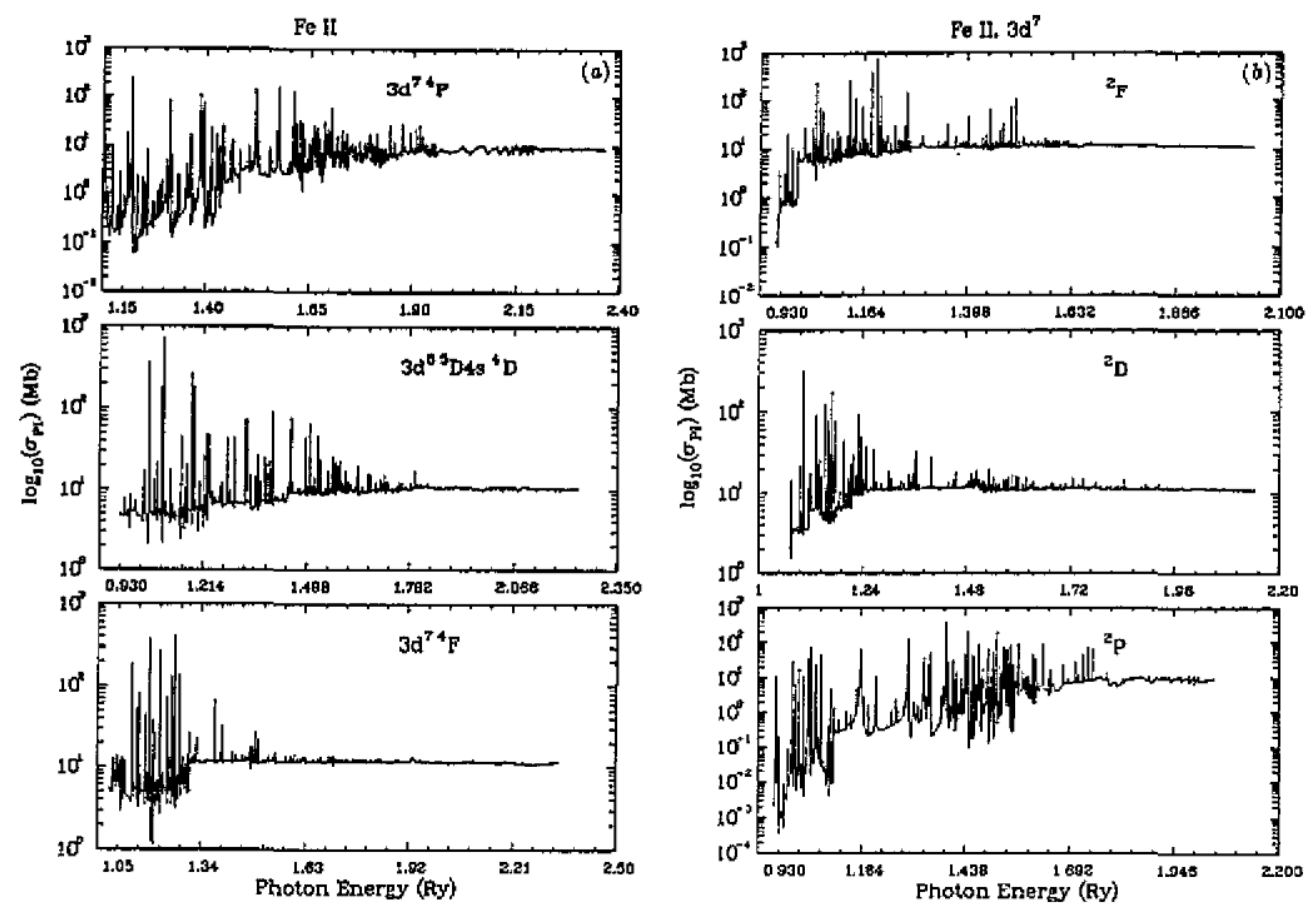

Figure 2. Photoionizatton cross sections of the metastable states of Fe II: (a) first three lowest quartet states, (b) three lowest doublet states.

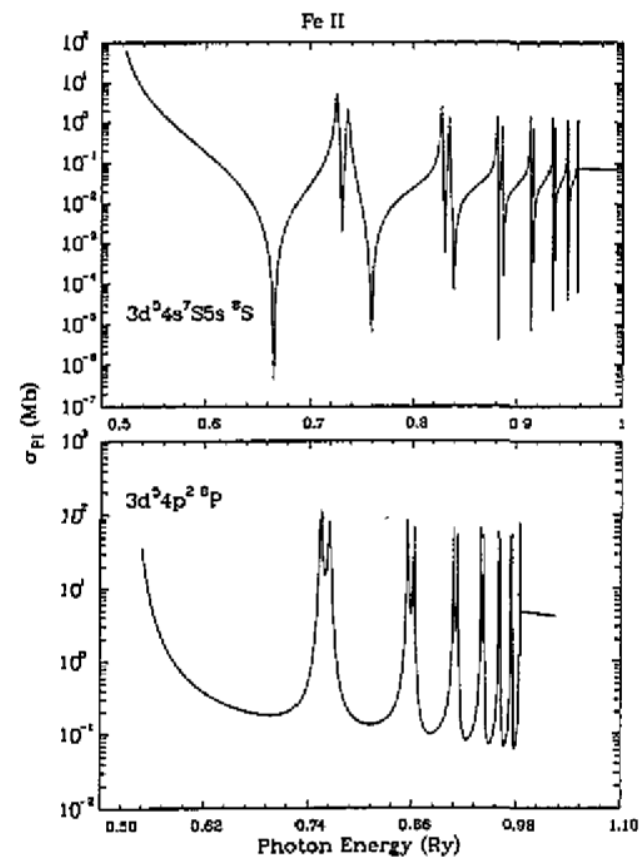

Figure 3. Photoionization cross sections of the two octet states, ${ }^{8} \mathrm{~S}$ and ${ }^{8} \mathrm{P}$, of Fe II. 


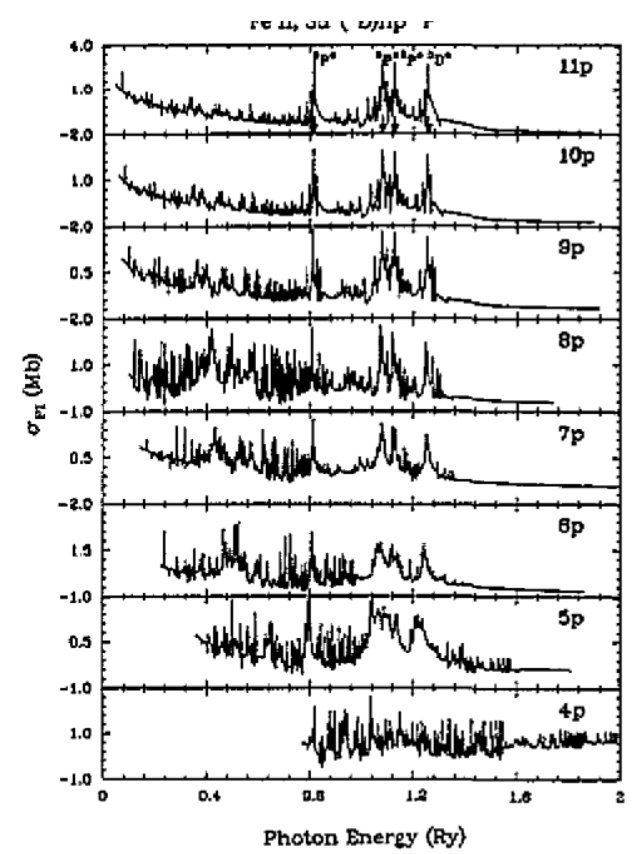

Figure 4. Photoionization cross sections of bound states along a Rydberg series, $3 \mathrm{~d} 6\left({ }^{5} \mathrm{D}\right) \mathrm{np}{ }^{4} \mathrm{P}^{\mathrm{o}}$, with $4 \leq \mathrm{n} \leq 11$ illustrating photoexcitation-of-core (PEC) resonances.

These resonances appear to be better resolved at higher excited states since the Rydberg resonances are usually weaker. The phenomenon of PEC resonances contradicts the usual assumptions of smooth hydrogenic behaviour of excited state photoionization cross sections, which may in fact be quite non-hydrogenic owing to the PEC features. It should be noted that even though there are more quintet states of Fe III in table 1 that are accessible through dipole transitions from the ground state, the figure shows only four since we treat several excited states to be degenerate as explained in section 3 and specified in the target states column of table 1.

\subsection{Monochromatic opacities}

The primary goal of the Opacity project is to calculate stellar opacities. Thus it is of some interest to examine the contribution to the opacities of a large calculation such as for Fe II reported herein. The total monochromatic opacity $K_{V}$ is obtained on summing the contributions from all of the radiative processes such as bound-bound transitions, bound-free transitions, Thomson scattering, and free-free transitions (the former two are the main contributors). The theoretical steps involved in the opacities calculations are summarized by Seaton (1987). The contribution to the monochromatic opacity from a bound-bound transition is obtained as

$$
\kappa_{v}=2 \pi^{2} e^{2} /(m c) N_{i} f_{i j} \phi_{v}
$$

where $N_{l}$, is the number density of the ion, and $\Phi_{\mathrm{v}}$ is a profile factor normalized to $\int \Phi_{\mathrm{v}} d v=1$; and that of a bound-free transition is

$$
\kappa_{v}=N_{i} \sigma_{\mathrm{PI}}
$$

Where $\mathrm{O}_{\mathrm{PI}}$ is the photoionization cross section. In terms of the monochromatic opacities, the flow 
of radiation through a plasma is governed by the Rosseland mean defined as

$$
\frac{1}{\kappa_{\mathrm{R}}}=\int_{0}^{\infty} \frac{1}{\kappa_{\nu}} g(u) \mathrm{d} u
$$

where

$$
u=\frac{h v}{k T} \quad g(u)=\frac{15}{4 \pi^{4}} u^{4} \frac{\exp (-u)}{[1-\exp (-u)]^{3}}
$$

The Rosseland mean is the weighted harmonic mean of the monochromatic opacities and $\mathrm{K}_{\mathrm{R}}$ is the Rosseland mean opacity. We have carried out separate calculations for the monochromatic and the mean opacities (using the OP code OPAC by Y Yu), for the single ion Fe II, with the new $R$-matrix data for the bound-bound and bound-free transitions from this work, and with the earlier $R$-matrix data of Sawey and Berrington (1992). At a temperature of $16000 \mathrm{~K}$ and a density of $10^{16} \mathrm{~cm}^{-3}$, we obtain values of $\mathrm{K}_{\mathrm{R}}$ to be 185 and 120 respectively, with the new and old data, resulting in an increase of over $50 \%$. The detailed monochromatic opacity spectrum of Fe II, with the two data

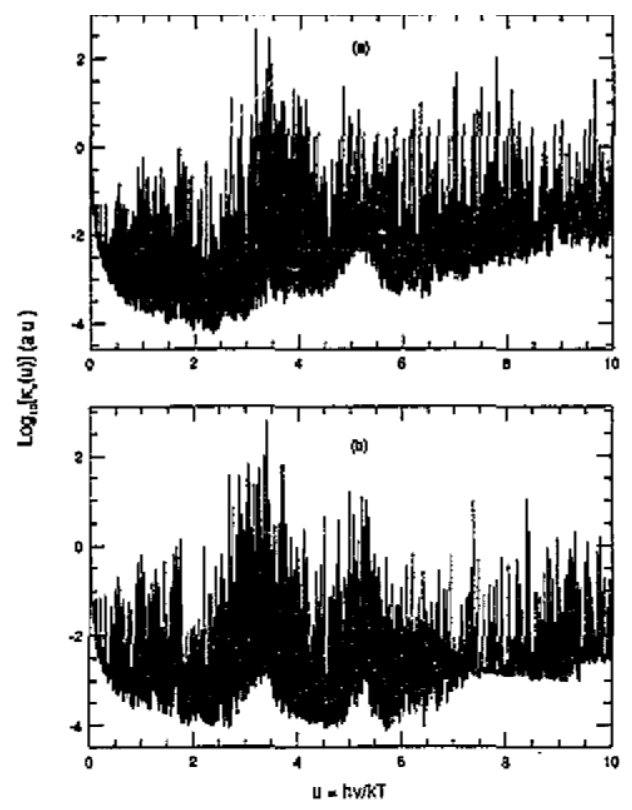

Figure 5. Monochromatic opacities, $\mathrm{K}_{\mathrm{V}}$, of Fe II at $\log T=4.2$ and $\log N_{e}=16$, (a) using the present radiative data and (b) the earlier data (Sawey and Berrington 1992).

sets, is shown in figure 5. In particular we note the rather large gap in the spectrum in the earlier data (bottom panel) around $u=3.5(5 \mathrm{eV})$, which has been filled in to a large extent by the new Fe II data (top panel). The Rosseland mean opacity, being a harmonic mean over the monochromatic opacities, is very sensitive to gaps or holes in the detailed spectrum, at low values of $h v / k T$ (equation (1)), and the feature in figure 5 is a significant contributor to the enhanced opacity. Also, in the high energy region, present opacities exhibit a rising trend and are more enhanced than those obtained using the earlier data. 


\subsection{Conclusion}

Extensive radiative calculations for Fe II are described and it is expected that the new data will be applicable to a variety of astrophysical applications, in addition to the original aim of the calculations of accurate plasma opacities. The $L S$ multiplet and fine structure oscillator strengths are compared with the available data and shown to be generally more accurate than other previous theoretical calculations (although there may be significant uncertainties for the weaker transitions). Most of the detailed photoionization data have been calculated for the first time. These are perhaps the largest close-coupling calculations carried out to date; yet we estimate that future relativistic calculations will be upto an order of magnitude more expensive in terms of computing resources and may not be feasible without massively parallel machines.

\section{Acknowledgments}

This work was partially supported by the National Science Foundation (PHY-9115057 and NASA LTSA program NAG W-3315). SNN aso acknowledges a research Fellowship by the College of Mathematical and Physical Sciences of the Ohio State University. The work was carried out on the Cray Y-MP at the Ohio Supercomputer Center (OSC). The authors are pleased to acknowledge the special allocation of memory and disk space by the OSC and the assistance of the staff in the execution of large jobs.

\section{References}

Allen C W 1976 Astrophysical Quantities 3rd edn (London: Athlone)

Berrington K. A, Burke P G, Butler K., Seaton M J, Storey P J, Taylor K T and Yu Yan 1987 J. Phys. B: At. Mol. Phys. 206379

Biemont E, Baudoux M, Kunrez R L, Ansbacher W, and Pinnington EH 1991, Astron. Astrophys. 249539

Eissner W, Jones M and Nussbaumer H 1974 Comput. Phys. Commun. 8270

Fuhr J R, Martin G A and Wiese W L I98S J. Phys. Chem. Ref. Data 17 Suppl. 4

Guo B, Ansbacher W, Pinnington E H, Ji Q and Berends R W 1992 Phys. Rev. A 46641 Hannaford P, Lowe R M, Grevesse N and Noels A 1992 Astron. Astropkys. 259301

Johansson S 1992 Private communication

Kurucz R L 1981 Semiempiricat calculation of gf values; Fe II (Smithsonian Astrophysical Observatory SpecialReport 390) (Cambridge, MA: Smithsonian Astrophysical Observatory)

Le Dourneuf M, Nahar S N and Pradhan A K (1993 J. Phys. B: At. Mol. Opt. Phys 26 LI Moore C E 1952 Atomic Energy Levels vol II, NBS Circular No 487 (Washington, DC: US Govt. Printing Office)

Nahar S N and Pradhan A K 1991 Phys. Rev. A 442935

Reiiman R F and Manson S T 1979 Asirophys. J. Suppl 40815

Sawey P M J and Berrington K A 1992 J. Phys. B: At. Mol. Opt. Phys. 251451

Schade W, Mundt B and Helbig V 1988 J. Phys. B: At. Mol. Opt. Phys. 212691

Seaton M J 1987 J. Phys. B: At. Mol Phys. 206363

Smith P L and Whaling W 1973 Astrophys. J. 183313

Sugar J and Corliss C 1985 J. Phys. Chem. Ref. Data 14 Suppl. 2

Yu Yan and Seaton M J 1987 J. Phys. B: At. Mol. Phys. 206409 